"This is the peer reviewed version of the following article: [Journal of Computer Assisted Learning, 2020, 36, (5), pp. 741-762] which has been published in final form at

[https://onlinelibrary.wiley.com/doi/10.1111/jcal.12444] purposes in accordance with Wiley Terms and Conditions for Self-Archiving." 


\title{
Where is the Teacher? Digital Analytics for Classroom Proxemics
}

\author{
Roberto Martinez-Maldonado ${ }^{a}$, Jurgen Schulte ${ }^{b}$, Vanessa Echeverria ${ }^{c}$, \\ Yuveena Gopalan ${ }^{\mathrm{d}}$ and Simon Buckingham Shum ${ }^{\mathrm{d}}$ \\ ${ }^{a}$ Faculty of Information Technologies, Monash University, Melbourne, VIC, Australia \\ ${ }^{b}$ School of Mathematical and Physical Sciences, University of Technology Sydney, Sydney, NSW, Australia \\ ${ }^{c}$ Human-Computer Interaction Institute, Carnegie Mellon University, Pittsburgh, PA, USA \\ ${ }^{d}$ Connected Intelligence Centre, University of Technology Sydney, Sydney, NSW, Australia
}

\begin{abstract}
The term "Classroom Proxemics" refers to how teachers and students use classroom space, and the impact of this and the spatial design on learning and teaching. This paper addresses the divide between, on the one hand, substantial work on proxemics based on classroom observations and, on the other hand, emerging work to design automated feedback that helps teachers identify salient patterns in their use of the classroom space. This paper documents how digital analytics were designed in service of a senior teacher's practice-based inquiry into classroom proxemics. Indoor positioning data from four teachers were analysed, visualised and used as evidence to compare three distinct learning designs enacted in a physics classroom. This paper demonstrates how teachers can make effective use of such visualisations, to gain insight into their classroom practice. This is evidenced by i) documenting teachers' reflections on visualisations of positioning data, both their own and that of peers; and ii) identifying the types of indicator (operationalised as analytical metrics) that foreground the most useful information for teachers to gain insight into their practice.
\end{abstract}

Keywords: positioning sensors * learning analytics * mobility tracking * learning design * physical learning spaces * motion sensors

\section{Introduction}

Previous research has found that teachers' positioning and mobility strategies in the classroom can strongly influence students' engagement (Chin et al., 2017), motivation (Fernandes et al., 2011), disruptive behaviour (Gunter et al., 1995), and self-efficacy (Koh \& Frick, 2009). These works, along with more classic literature looking at the position of the teacher in relation to students' locations (see review by O'Neill \& Stephenson, 2014) point to the strong influence of teacher's positioning on learning, and to the importance of understanding how teachers use, or could make use, of learning spaces. Inspired by McArthur's work (2008), this work can be referred to as Classroom Proxemics to account for the broader study of how teachers and students use the classroom space.

Teachers are often encouraged to adopt certain positions or move following specific patterns in the classroom. Some teaching guides (e.g. Arends, 2014; Jones et al., 2007; Scrivener, 2005) encourage novice teachers to adopt some strategies (e.g. standing at the front of the class, circulating or getting closer to students) at various stages of a classroom session, depending on the students' task. Other guides prompt teachers to find an inner loop in the classroom and keep circulating for all students, to maintain a short average distance from the teacher (e.g. Jones, et al., 2007). Others provide paper-based tools (e.g. MO-SW-Positive Behavior Support, 2019) to help teachers reflect on aspects such as whether they were in continuous movement, standing in targeted areas or keeping close proximity to most of the students. Unfortunately, most of these teaching guides do not refer to the evidence used to prescribe such strategies. In fact, McArthur (2015) reported that research on the use of the classroom space lacks empirically-based studies that could provide evidence to strengthen (or adjust) the prescriptions in those teaching guides.

Novice teachers can receive feedback on their classroom positioning from peers or experienced teachers observing their classes (Britton \& Anderson, 2010) which, arguably, can be 
susceptible to bias (Shortland, 2004) and hard to scale up (Fletcher, 2018). Yet, a far larger number of teachers, particularly in higher-education, receive no pedagogical training nor feedback on classroom proxemics (Ellis et al., 2016; Gerritsen et al., 2018). Besides aspects related to the time and resources needed to train such teachers (Robinson \& Hope, 2013), this is certainly also due to the lack of evidence that can be used to provoke reflection on the use of the classroom space.

The above suggests that there is a timely opportunity to use emerging, inexpensive technology to provide evidence of teachers' positioning in the classroom. Automated indoor positioning has witnessed an increase in interest in the last decade (Brena et al., 2017) as a technique to provide continuous real-time localisation of objects or people within a closed space. This is commonly achieved by triangulating the distance between a wearable device and fixed anchors (Alarifi et al., 2016) or by estimating the location of moving objects based on video (Tsai et al., 2016). These approaches could be implemented in classrooms to transform ephemeral positioning strategies, which can be hard to 'see with the naked eye', into fine-grained digital traces of how people move in the classroom. Recent small-scale studies have explored the potential of using indoor positioning to provide user interfaces that alert teachers which students have been paid less attention to in the classroom (An et al., 2018; Martinez-Maldonado, 2019). However, to create interfaces that effectively support teaching practice, more work is needed to understand how positioning data can be rendered in pedagogically meaningful ways, to inform teachers' reflection and development.

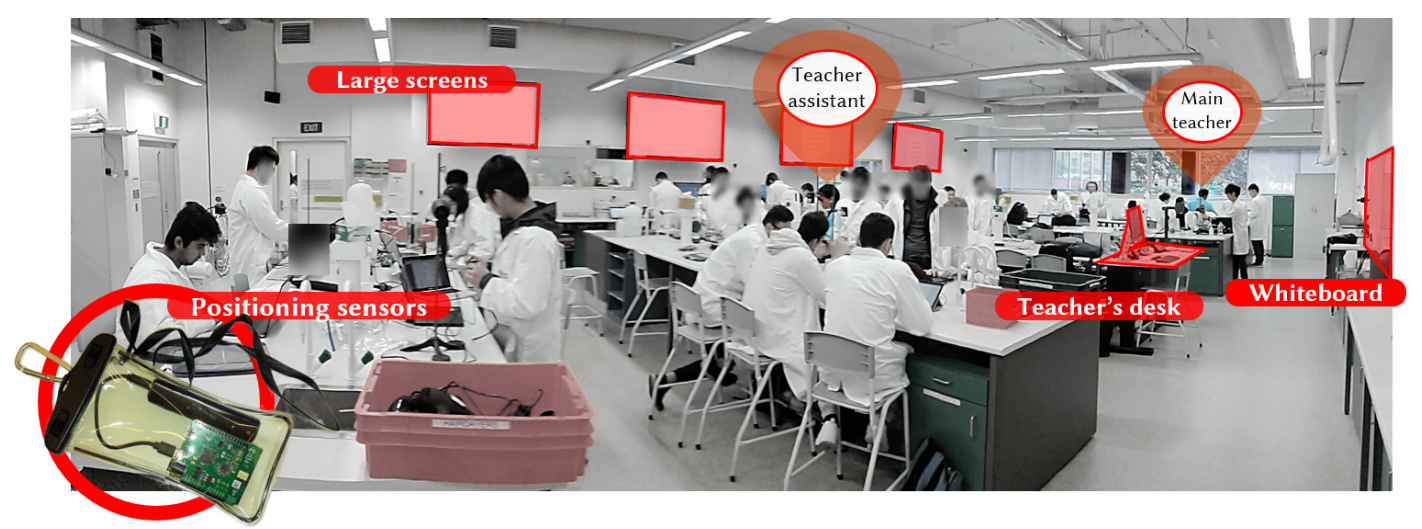

Figure 1. An authentic class, led by two teachers, in a physics laboratory classroom. The positioning sensor was contained in a badge worn by each teacher under the laboratory coat (left).

This paper addresses the divide between the substantial work on classroom proxemics based on qualitative observations, and the emerging work aimed at creating interfaces to aid teachers in the classroom. The paper presents an authentic study driven by a teacher's inquiry process in the context of physics education. Positioning data from four teachers, a lead and an assistant co-teaching in pairs, was captured using positioning sensors during three weeks in a laboratory space (Figure 1). These data were analysed, visualised and used by teachers to compare their three very distinctive learning designs. This paper documents teachers' reflections provoked by those visual representations and the emerging analytics (metrics) that could be useful for teachers to gain insight into the data.

The rest of the paper is structured as follows. The next section introduces theoretical foundations and the technical state-of-the-art in the field of classroom proxemics. Section 3 presents the learning context and the teacher's inquiry that motivated this study. Section 4 presents the study design, the technology used and the analysis methods. Section 5 presents results from the study. Section 6 discusses the implications for broader research and practice, limitations encountered, and potential avenues for future work. The paper concludes with an overview of the paper in Section 7. 


\section{Background}

This section presents: i) a definition and foundations of classroom proxemics; ii) an overview of classic and current work that has focused on studying teachers and students positioning in relation to epistemic and physical aspects of learning spaces; and iii) a discussion of related research aimed at providing automated mechanisms to analyse or use positioning classroom data.

\subsection{Foundations of classroom proxemics}

Different terms have been used to refer to a common aim: studying how teachers and students make use of the classroom space. The term Instructional Proxemics (Chin, et al., 2017; McArthur, 2015), for example, has been used to refer to the study of teachers' positioning in a class in relation to existing classroom layout and students' seating arrangement. Similarly, Lim et al. (2012) proposed the term Spatial Pedagogy to refer to the meanings that zones of the classroom may take on, because of the positioning and distance of such spaces relative to students, teachers and resources, and the instructional tasks and interactions occurring in the classroom. Before these authors coined these terms, others studied the use of learning spaces by focusing on aspects such as positioning and localisation (terms often used interchangeably), proximity, mobility, and seat arrangement. These and other works are discussed in the next sub-section.

Inspired by McArthur's work (2015), the term Classroom Proxemics is proposed to refer to the research space targeted in this paper. First, this term points at foundational work by Hall (1966) who defined proxemics as the study of culturally dependent ways in which people use interpersonal distance to mediate their interactions. This work has been widely used in architecture and interior design, including the design of learning spaces (Thompson, 2012). Second, inspired by work on orchestration (Dillenbourg et al., 2011), the classroom can be considered as the ecological unit of analysis. The classroom includes social, epistemic and physical aspects, that are quite intertwined (Goodyear et al., 2018) and teachers may have varied degrees of control over these aspects according to their pedagogical approach and the tasks unfolding in them. In this paper, the notion of Classroom Proxemics is used as a theoretical lens to generate understanding about how teachers make use of the classroom space in relation to students' positions and available resources. The next section presents an overview of research on teachers' positioning in the classroom.

\subsection{Empirical research on classroom proxemics}

There is a long history of research studying the relationship between the classroom as a built environment, and the teaching and learning processes that unfold in it, but it is fragmented across multiple areas (McArthur, 2015). Seminal work investigating the relationship between pedagogy and the learning space dates back to the 19th century. The most significant of this work was that of Barnard (1854) who, based on thorough classroom observations, prescribed a series of classroom arrangements to maximise teachers' surveillance of students and student's attention directed to the teacher, leading to the 'traditional' lecture-based seating arrangement. This and subsequent works (see reviews by Haghighi \& Jusan, 2012; Wannarka \& Ruhl, 2008) have been foundational for the body of literature focused on learning spaces architecture. However, more recent work has focused on proximity aspects of the teacher in relation to students' learning.

Kounin (1970) analysed classroom videos to understand how different teachers' behaviours affected students in terms of discipline and socio-emotional dynamics. Rubin (1972) obtained evidence from classroom observations and students' questionnaires to investigate how the location of the teacher in relation to the classroom furniture can affect the communication processes constantly 
occurring between the teacher and students. Gunter, et al. (1995) stated that teachers should be aware of proximity control strategies, and move about the classroom to keep teacher-student interactions evenly distributed and reduce the amount of disruptive behaviour. Giangreco et al. (1997) performed observations to understand the impact of teachers' proximity to students with disabilities, reporting a tension between interference, and students developing a sense of ownership of their work, by looking at how close the teacher/educator was to them. Burda and Brooks (1996) demonstrated that students in closer proximity to the teacher are also the ones that reported being more highly motivated.

Lim et al. (2012) conducted an in-depth analysis of two teachers using the same learning space with an identical layout. The authors produced state diagrams to represent the spaces of the classroom in which the teacher was moving, the frequency with which a space was visited, and transitions. They suggested the need for multimodal approaches to understand how teachers use the classroom resources, including the analysis of language, gesture, positioning and movement. Similarly, Chin, et al. (2017), used classroom observations, field notes, interviews, and audio and video recordings to characterise the activity of four teachers teaching in the same classroom. Their results suggested that teachers' positioning strategies are strongly shaped by the existing classroom layout, students' seating arrangement, and the instructional activity of the day. These conclusions are aligned with classic research on learning spaces in general (see review by Higgins et al., 2005), which demonstrates that conclusions can rarely be generalised because the learning environment is multifaceted, and research approaches often do not embrace such complexity.

In sum, the research described above shows how teachers' positioning in the classroom can strongly affect learning. However, most analysis approaches have been based on self-report questionnaires, and observations made of a small number of classes. This points at limitations of these observational studies regarding the kind of evidence that can be collected (which can be susceptible to bias), the scalability of the studies, and the precision of relative distances which are critical for analysing proxemics. This motivates the need for tools to automate the collection of accurate evidence that can facilitate the scalability of classroom proxemics studies. The next section therefore describes the recent flurry of research developing automated mechanisms to study teachers' classroom positioning and movement.

\subsection{Analytics and interfaces for indoor positioning in learning spaces}

There has been a growing interest in exploring physical aspects of the classroom using automated techniques (Chua et al., 2019). For example, video analysis has been used as a way to identify students' posture and affective states during a lecture (Raca et al., 2015) or to quantify the number of interactions between lecturers and students (Watanabe et al., 2018). Prieto et al. (2018) modelled teachers' activity based on multimodal wearable sensors (an eye tracker, an accelerometer, an electroencephalogram device and a camera). This work pointed to the potential of automatically capturing traces of teachers' activity to identify teaching tasks. Bosch et al. (2018) also modelled teachers' behaviours (such as walking or gesturing) during a lecture using video data. Similarly, Howard et al. (2018) described a classroom recording system based on video and audio. By applying a motion estimation algorithm to classroom videos, they showed how the relative position of the teacher from two different cameras could be helpful to mine movement patterns. However, a key limitation of video-based approaches is that they depend on the position of static cameras and do not provide precise positions of the teacher. Moreover, video-based approaches may work for research purposes but can raise potential ethical issues related to unintended surveillance, making it impractical for regular classroom use (Derry et al., 2010). 
A range of technologies has started to be used to record students' positions automatically. For example, Schneider and Blikstein (2015) used a depth camera in an experimental setup to identify the distance between two students as a proxy of collaboration. Shu et al. (2016) paired an indoor positioning system with augmented reality technology to help students navigate in a library. Some work has also emphasised the potential of using positioning sensors to track high-performing team members for healthcare (Echeverria et al., 2018) and firefighter training (Wake et al., 2018).

These studies illustrate how multimodal data can serve to complement the scholarly analysis of classroom proxemics, but two recent efforts have gone beyond collecting data for research purposes by proposing teacher-facing interfaces to improve classroom awareness. The first of these systems is ClassBeacons (An, et al., 2018) which visualises the amount of time a teacher has spent near to groups of students, through a physical device (a lamp) located at each group's table. Using a rule-based algorithm, the lamp changes its colour in a range from yellow to green, with yellow indicating the teacher has not spent time close to the device. The authors reported that teachers experienced increased self-awareness in terms of teacher-student time, but they also reported potential negative effects, such as disruptions and students' complaints as a result of the presence of the device. Similar work was conducted by Martinez-Maldonado (2019) using a private, small display to show a floor map of the classroom highlighting which student groups were less well attended by the teacher. In this study, a teacher warned of the potential misinterpretation of the data if the learning design is not considered by the warning system. This question is central to the work reported in this paper.

The work presented in this paper goes beyond previous work by addressing the need for automated and scalable approaches to capture evidence of classroom proxemics (discussed in section 2.2) and the need for contextualising positioning data automatically captured via sensors (discussed in this section). Much work needs to be done to identify the kind of reflections that teacher's positioning data can provoke, and the metrics that may be useful for sensemaking, in order to understand the potential of using these data to support teachers' professional development. The following sections describe an authentic study that contributes to addressing this gap.

\section{Purpose}

\subsection{Research questions}

Our research question, motivated by the research gap identified in Section 2.3 is the following: What are the potential ways in which teachers can effectively use positioning data to gain insight into their classroom practice? To the best of our knowledge, no previous work has focused on understanding teachers' reactions to classroom positioning data, and it is not clear what kinds of metrics can be automatically extracted from these data. This paper contributes to addressing this gap by responding to the following two research sub-questions:

\section{Q1 What are teachers' reflections on visual representations of low-level positioning data? \\ Q2 What kinds of positioning metrics can support teachers' reflection on classroom proxemics?}

\subsection{Learning context}

The research sub-questions are addressed through an authentic study conducted in the context of authentic laboratory classes of the first-year undergraduate unit 'Physical Modelling' taught at the Faculty of Science of the University of Technology Sydney. Laboratory learning is a pedagogical approach aimed at providing students with a space for them to observe, practice, and experiment with materials, tools, phenomena, and ideas (Ka Yuk Chan, 2012). The coordinator explained that, in their 
laboratory program, they distinguish the following three types of small-group learning experiences in which students are grouped in teams of 2-3 individuals:

LD1) Prescribed laboratory class (Prescribed.Lab), in which procedures to acquire experimental data are well defined by the teacher and prescribed to the students in the form of a laboratory guide. The experimental setup is the same for all students, to ensure that all learn the same facts and arrive at the same pre-set outcome. For example, in the study presented in this paper, the prescribed experiment involved measuring periodic oscillation using a pendulum experimental setup. In the classroom, teams set up the experiment on benches and teachers supervise or help students according to their progress.

LD2) Authentic project-based laboratory class (Project.Lab), in which the learning design is aimed at resembling authentic industry projects. For example, in the study presented in this paper, the coordinator partnered with an external consumer advocacy organisation which provided consumer products (e.g. vacuum cleaners and pedestal fans) for students to formulate product testing projects. In this case, each team works in a different project.

LD3) Authentic theory-testing laboratory class (Theory.Lab), in which four experiments are set up by the teacher on laboratory benches before the class starts (for example, measuring conservation of mechanical energy using an inclined plane). Teams are asked to predict the outcome of each experiment and then have a close look at the experiment but are not allowed to execute it. This is aimed at provoking students' reflection on the underlying assumptions that underpin their simplified formulas. Teachers work as demonstrators repeating each of the 4-5 experiments on demand for students.

In terms of classroom proxemics, the coordinator of the unit believed that "the proximity of a teacher to a particular student team, and the frequency of visits to a group, can tell a story about the attention that the teacher is giving to a particular group, and the group's need for attention or teacher advice". The teacher specified that he would look at how the different teachers who lead the learning designs move around and use the laboratory space. This constituted an authentic teacher inquiry process (Dana \& Yendol-Hoppey, 2014; Erickson \& Clarke, 2003) in which the coordinator seeks to assess his learning designs, using evidence from learning analytics innovations (Melero et al., 2015; Persico \& Pozzi, 2015; Rodríguez Triana et al., 2014; Sergis \& Sampson, 2017).

\section{Study, materials and methods}

\subsection{Classes observed, participants and the learning space}

The study presented in this paper focuses on weekly 2.5 hour classes (average actual duration $2.22 \pm$ $0.09 \min , n=12$ ) in which students work in small teams advised by a supervising teacher (main teacher) and a teaching assistant, enacting the three learning designs (LD1, LD2 and LD3). The classroom (16.81 x 9.86 meters: Figure 2$)$ is equipped with six work benches, two regular tables, one whiteboard, a teacher's desk equipped with a computer connected to four large screens, and multiple laboratory tools and devices (see also Figure 1). Each class typically has from 30 to 40 students working in small teams of 2-3. This means there commonly are from 10-13 teams of students in each class. The study focused on twelve randomly chosen classroom sessions (1-12) conducted in weeks 4 , 5 and 6 of a semester in 2018. The classes were conducted with the same students in the same classroom for each of the weeks: classes 1-4 in week 4 enacting Prescribed.Lab; classes 5-8 in week 5, with the same students, enacting Project.Lab; and classes 9-12 in week 6, enacting Theory.Lab. 


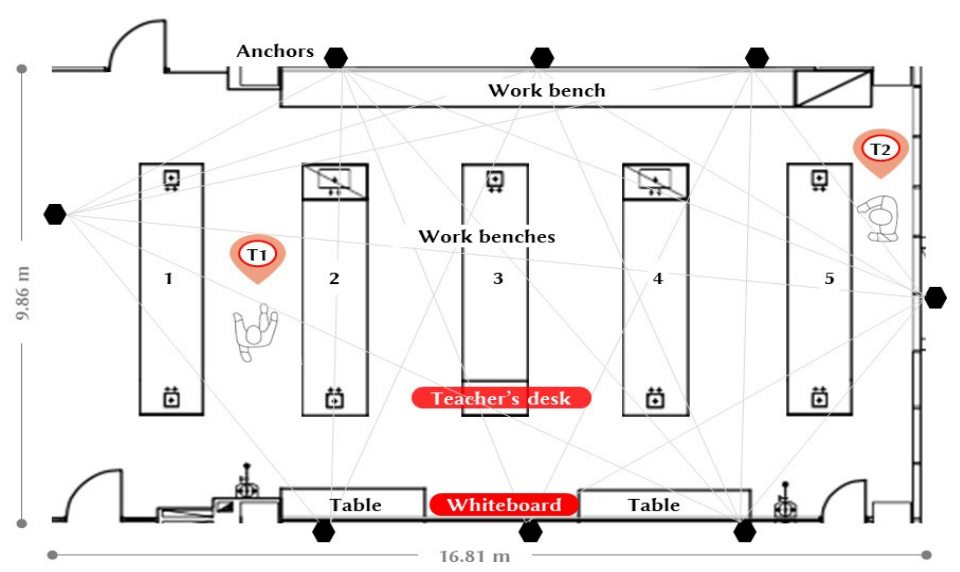

Figure 2. Floor plan of the classroom targeted in this study. Eight wall-mounted anchors triangulate the position of the teachers (T1-2) and furniture in the learning space.

Five teachers (T1-T5) were involved in these classes. T1, the coordinator of the unit, designed the learning tasks but did not teach any class (acting as the 'learning designer'). T2 was the main teacher for all 12 classes, and the other three teachers (T3-T5) participated as assistants (see Table 1).

Table 1. Details of classes observed in this study.

\begin{tabular}{lc|ccc|c} 
Learning design & $\begin{array}{c}\text { Class } \\
\text { session }\end{array}$ & Main teacher & Assistant & \# of students & $\begin{array}{c}\text { Duration } \\
\text { (hours) }\end{array}$ \\
LD1 & 1 & T2 & T3 & 36 & 2.20 \\
Prescribed.Lab & 2 & T2 & T4 & 37 & 2.12 \\
(Week 4) & 3 & T2 & T5 & 39 & 2.00 \\
\hline LD2 & 4 & T2 & T5 & 33 & 2.20 \\
Project.Lab & 5 & T2 & T3 & 34 & 2.15 \\
(Week 5) & 6 & T2 & T5 & 38 & 2.30 \\
& 7 & T2 & T5 & 35 & 2.30 \\
LD3 & 8 & T2 & T5 & 30 & 2.30 \\
Theory.Lab & 9 & T2 & T4 & 30 & 2.25 \\
(Week 6) & 10 & T2 & T5 & 33 & 2.30 \\
& 11 & T2 & T5 & 34 & 2.30 \\
\hline
\end{tabular}

\subsection{Data Collection}

Indoor positioning data. Teacher's positioning in the classroom was automatically captured through a custom-made wearable badge based on the Pozyx.io ultra-wideband (UWB) sensing system (Figure 1) at $2 \mathrm{~Hz}$ (two data points per second) average sampling rate. Eight 'anchors' were installed on the classroom walls to triangulate the ( $x$ and $y$ ) positions of the badges (Figure 2, $)$ ). UWB sensors, unlike other technologies such as infra-red, Bluetooth and ultrasound sensors, do not require a straight line of sight and are not affected by other digital devices in the room (Alarifi, et al., 2016). This makes them suitable for tracking activity in classrooms in which multiple mobile phones, computers, and appliances are worn or used by students. Additionally, the low cost of UWB equipment is making it increasingly affordable to install in many classrooms. Properly configured, it provides location accuracy within a $10 \mathrm{~cm}$ error.

Furniture, experiments and students' positions. In this study, the focus is on tracking the positions of the teachers in the classroom with reference to fixed characteristics of the learning space 
(e.g. furniture and equipment) and the positions of experimental setups as proxies of students' positions. Given the large number of teams in each class (10-13), the location of students' experiments was captured and integrated into the positioning system by an observer through an observation console. This enabled an observer to configure the tracking tool by registering where the experiments were located, by clicking on the floor plan of the classroom. For Prescribed.Lab and Project.Lab, teams remained most of the time close to where they installed their experiments (Figure 3, left and centre). For Theory.Lab, teams had to move to each experiment setup and these were recorded by the observer (Figure 3, right).
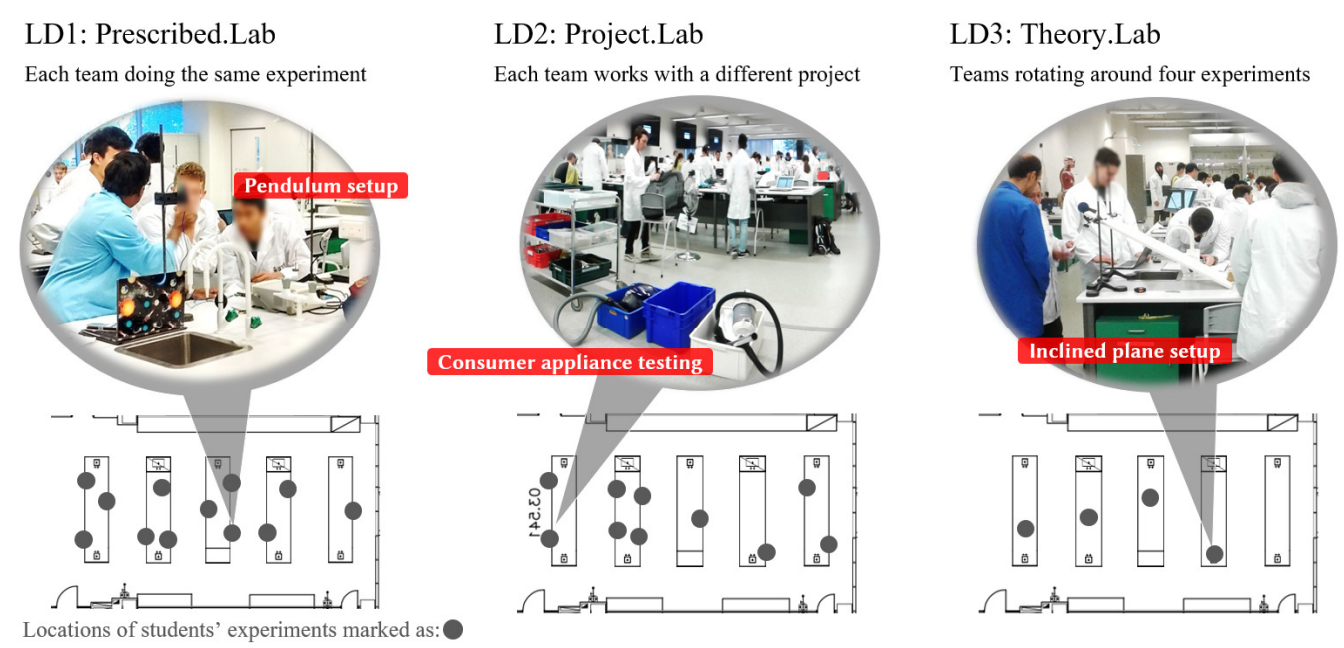

Figure 3. Locations of students' experiments captured by an observer. Left: For LD1, all teams installed a similar experimental setup on a bench. Centre: For LD2, teams installed an appliance at the benches or on the floor. Right: For LD3, teams had to move to each of the four experimental setups, sitting on different benches.

\subsection{Study design and analysis}

A human-centred approach (Giacomin, 2014) was adopted to address the research questions. This means that the coordinator of the unit/learning designer, and the main teacher who ran the classes, became partners in the inquiry process. A set of interviews and validation sessions were conducted with them, structured using the Learning Analytics Translucence Elicitation Protocol (MartinezMaldonado et al., 2020a; Prestigiacomo et al., 2020). This is an elicitation process that includes five steps to design for effective use of learning analytics systems: 1) Identifying stakeholders; 2) Identifying relationships of influence and power (amongst them); 3) Documenting the teacher's inquiry (eliciting the hypotheses that educators can test with evidence); 4) Defining the translucent system characteristics (the types of information that different people may require, interaction features and access rules); and 5) Designing for orchestration (translating information requirements into strategies before/during/after class).

Each step in this process includes a series of questions to which educators are invited to respond. Figure 4 outlines the sessions that were conducted with the goal of addressing our two research questions.

Steps 1 and 2. Two 'exploratory' unstructured interviews, conducted with T1, served to generate a deep understanding of the roles of each relevant stakeholder and their relationships (Steps 1 and 2), and identify the initial questions that motivated the inquiry (Step 3: a concise description of these was presented above). After the classes were delivered and positioning data was collected, two sets of validation sessions (A and B) were conducted (Steps 3-4), which we elaborate next. 


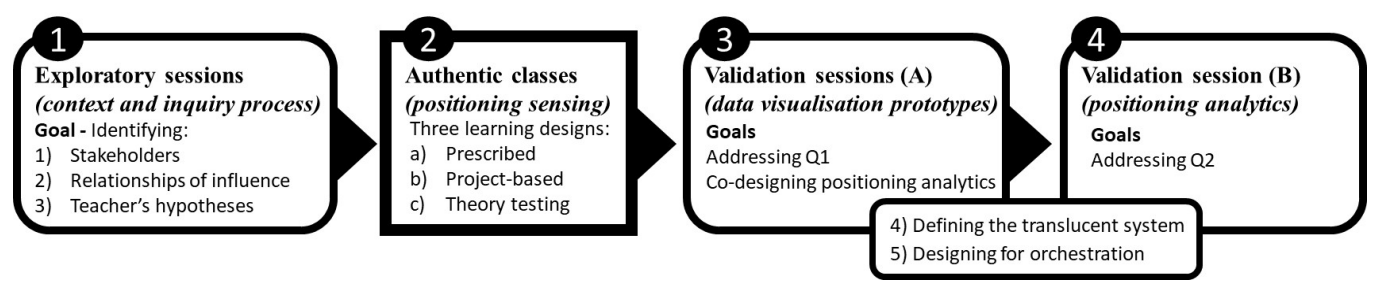

Figure 4. Human-centred elicitation and validation process for addressing the research questions.

Step 3. Validation sessions A. The first set of sessions was conducted with the coordinator and the main teacher (T1) with the aim of i) addressing question "Q1" and ii) identifying the potential quantitative metrics of positioning data. From classroom observations, a common macro-script for the three learning designs was defined as follows. Phase 1 includes the main teacher explaining the goals and giving instructions to students from the teacher's desk (average duration $11.5 \pm 8$ minutes, $\mathrm{n}=12$ ). Phase 2 corresponds to the period in which all students start working on the experiment(s) of the day in small teams ( 1.36 hours $\pm 25 \mathrm{~min}$ ). Phase 3 corresponds to the time when some teams complete their experiments and start to leave the classroom ( $32 \pm 25$ minutes).

These sessions focused on documenting the teacher's reflections on positioning data captured in phase 2 of each class, and were conducted as semi-structured interviews as follows:

1) Teachers were asked to describe the learning designs and the usual classroom dynamics of the three weeks that were observed, and comment on what they expected to see in the positioning data for each week (the teacher's hypotheses - reinforcing Step 3 of the elicitation process).

2) A think-aloud protocol was followed to document how teachers explored the positioning data. Data were presented to teachers as indoor maps containing positioning data of all the classes (e.g. Figure 5, A). On request, the same data was made available to teachers for each class divided into quartiles (of $24 \pm 5$ minutes each as in Figure 5, B). Thus, in total, 12 sets of 5 maps were presented to each teacher. The maps were generated by normalising the positioning data to $1 \mathrm{~Hz}$ to make them comparable. The maps were printed on paper using a visual impairment aware colour palette (RGB \#1170AA to show data points for the main teacher; \#FC7D08 for the second teacher; and \#57606C for students' positions).

3) A post hoc interview was conducted to identify potential uses of the data to support professional practice (Step 4 of the elicitation protocol) and classroom orchestration (Step 5). This included questions suggested in the LATEP protocol, which are summarised as follows:

- Visibility. Key question: What is being made visible through positioning data? Secondary questions: How do you think these data should be visualised? What kind of metrics would you be interested to see? What other sources of data should be considered?

- Awareness. Key question: What would you do with these data? Secondary questions: What do you think would be useful for the teacher: to have during or after the class, to be notified about or to be aware of when someone else looks at his/her data?

- Accountability. Key question: What are the implications of showing these data to others? Secondary questions: Who do you think should look at these data? Should the data be given to: teachers themselves, other teachers (e.g. novice/inexperienced), academic units, or students? Do you think these data can be used to assess the performance of the teachers?

The outputs from these sessions were the teachers' reflections on visual representations of positioning data about the four teachers enacting the three learning designs, and a list of potential metrics that could be useful to support teacher's inquiry quantitatively. 

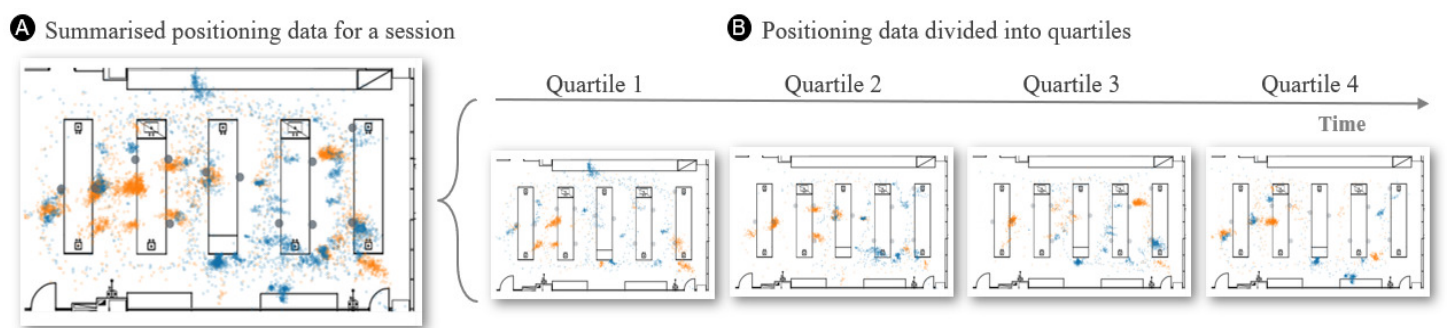

Figure 5. One of the 12 sets of positioning data maps presented to teachers (session 1, phase 2).

Step 4. Validation session (B). A think-aloud protocol was used to document how the coordinator reacted to the quantitative information calculated for each of the 12 classes. This served to explore the relationship between his beliefs about how the teachers under his supervision commonly enact his learning designs, and the resulting positioning metrics. Each metric will be introduced below, as the educator's reactions are discussed. The analysis of the coordinators' comments focused on identifying how the quantitative positioning data contributed to identify i) differences between the three learning designs or ii) differences between teachers, and iii) to spark further teacher's questions.

The next section provides insight into the role of positioning data in teachers' inquiry.

\subsection{Reflections on the positioning data}

\section{Analysis and results}

One researcher was present in each validation session. Episodes in which teachers deeply analysed particular data maps were identified by two researchers from the transcribed video recordings of teachers' reflections. Statements of interest were jointly coded by the two researchers following an inductive thematic analysis approach (Braun \& Clarke, 2006). Then, resulting coded statements were examined by authors who had several discussions to select instances that effectively reflect potential ways in which teachers can effectively use positioning data to gain insight into their classroom practice. Four themes emerged, namely:

1) Territoriality, which included observations on how teachers stayed in certain classroom spaces;

2) Use of the classroom space according to the learning design, which included explanations of the teacher's movement based on what students were expected to do;

3) Differences between teaching assistants, which included explanations of assistants' movements based on the main teacher's classroom experiences; and

4) Temporality, which included insights revealed by presenting partial summaries of positioning data.

These themes are presented below in the form of vignettes that illustrate the kind of reflections teachers made on 19 out of the 25 maps they deeply explored (coverage $76 \%$ ).

\subsubsection{Vignette 1: Territoriality}

Three out of the four classes (1, 3 and 4) in which the first learning design (LD1) was enacted, were pointed to by teachers as the only ones in which positioning data showed a clear division of the classroom space (session 2 is discussed in depth under Theme 3 in Sec.5.1.3). Figure 6 (left) shows one example (session 4) in which the teaching assistant focused on the two first benches where students worked (Figure 6, Zone A) and the main teacher on the other three benches (Zone B). By contrast, this clear division of the classroom was not evident in most of the other classes (LD2 and LD3, examples in Figure 6, centre and right- with the exception of class 5 which showed some territoriality but was not pointed by the teachers). 
LD1: Prescribed.Lab (session 4) Classroom benches distributed between the teacher assistant and the main teacher

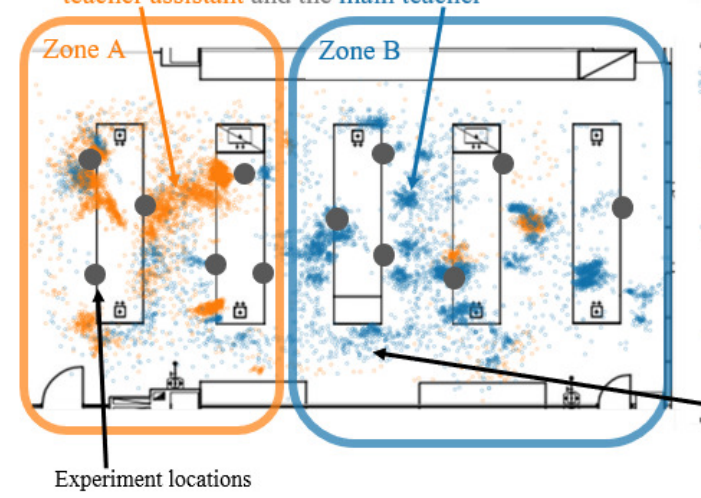

LD2: Project.Lab (session 7)

Both teachers present almost everywhere the classroom
LD3: Theory.Lab (session 11)

A large zone of the classroom remained unused by both teachers

by both teacher

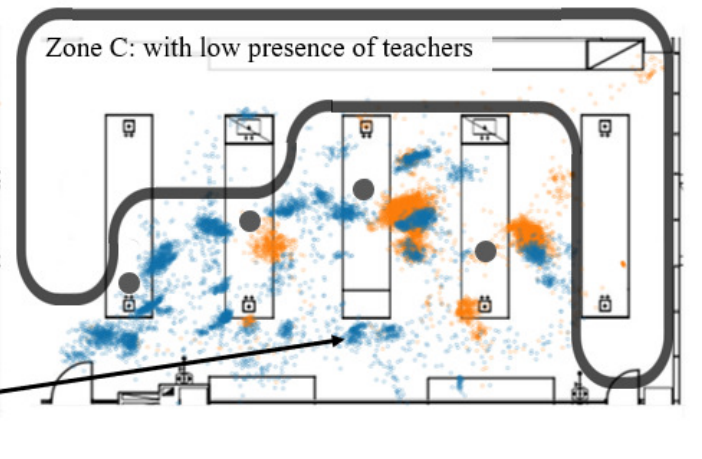

Higher presence of both teachers near teacher's desk in LD2

Figure 6. Three example maps of sessions 4, 7 and 11 (taught by the same teachers) in which territoriality aspects were highlighted by teachers. T2's data points are shown in blue and T5's in orange.

LD1: Prescribed.Lab (session 4)

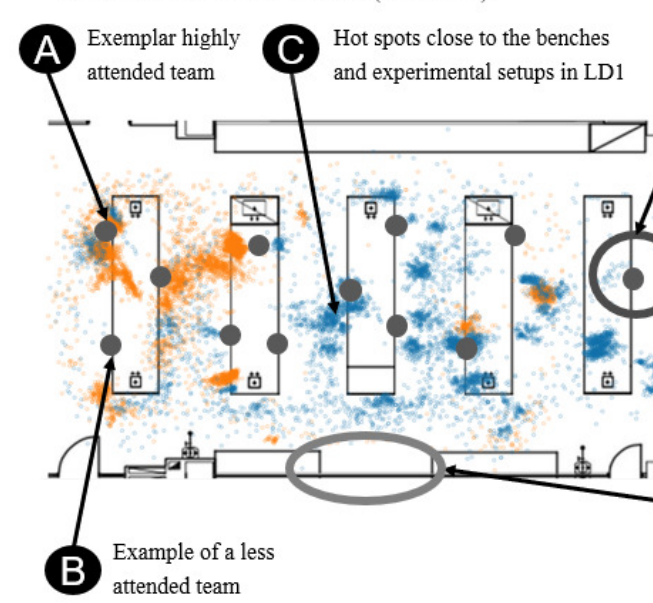

LD2: Project.Lab (session 7)

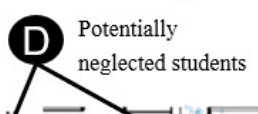

E Additional benches
LD3: Theory.Lab (session 11)

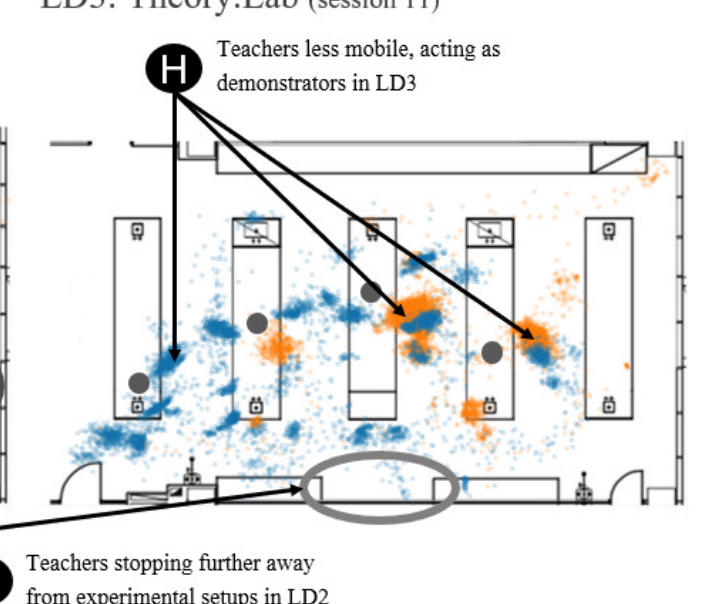

Figure 7. Three annotated maps in which specific aspects associated with classroom proxemics were explained by teachers based on the three different learning designs (LD1-3). 
Recall that Teacher (T1) coordinated the course and defined the learning designs. He reflected on territoriality as follows: "For these sessions [of LD1] there is a separation because [teachers] are allocated to [specific] tables. We don't see that here in the authentic experiment (LD2). It's more spread, the blue and the orange go all over the place". This teacher was not surprised since he confirmed the following: "That's the instruction that they get. I tell the main teacher (T2), you get an assistant and employ the assistant in the best way, maybe you split up the tables with that assistant".

However, when T2 was confronted with the data, he was surprised in finding this pattern in some of his classes. This was initially made evident through the following reflection: "If we look at the blue (his own data in LD1), especially sessions 3 and 4, why is there less attention to half of the class than the ones in the authentic experiment (pointing at sessions 7 and 8)? Maybe due to the second person attending them (pointing at Zone A in Figure 6)". This partly contradicted the expectation of $\mathrm{T} 1$, pointing at a potential emerging classroom dynamic. T2 later confirmed this as he kept reflecting on this as follows: "We don't [explicitly] organise ourselves by benches at the beginning. If I notice that [the assistant]'s giving some help, attending to those [students] regularly, then I'll go to the other [students] and give help to them".

Another difference in terms of territoriality highlighted by teachers was in the four classes in which LD3 was enacted (9-12, e.g. see Figure 6, Zone C). These were the only classes in which large classroom zones were not used (very low or no presence of both teachers). This confirms one initial hypothesis that T1 had, explained as follows: "In [LD3] the teacher runs the experiment so there should be less running around. Students walk towards each experiment located on the benches". Then, T1 reflected on the LD3 sessions as follows: "[LD3] is a field of work that students do on the benches, so it could be easiest [for teachers] to stay close to the bench, show them the events around that experiment, and then ask questions to guide the students in the right direction".

Finally, teachers highlighted that the four classes in which LD2 was enacted (5-8) presented a high presence of one or both teachers near the teacher's desk for long periods of time (Figure 6, Point A). This was explained by T1, by particularly comparing Point A in Figure 6 for sessions 4 and 7, as follows: "We see there's a distinct difference here (pointing at the data points around the teacher's desk). For [LDI] students need a lot of assistance and inquire a lot because they are commonly not prepared. So, they are sitting there, so the teachers go around responding to every little question. Whereas for this one (LD2), the students know what they are going to do and what they need". Then, T1 explained why teachers might stay longer at the teacher's desk as follows: "For [LD2] students need assistance on punctual topics [...] so they're all targeted interactions. This requires less scattered running around for the teachers". However, T2 also spent a lot of time by the teacher's desk in other classes (although not highlighted by the interviewed teachers). This points at potential overinterpretation issues that should be considered in the design of representations of teacher's positioning data (to be discussed in Section 6.2.2). There were other remarkable reflections on other classroom spaces, which are discussed in the next vignette.

\subsubsection{Vignette 2: Use of the space according to task differences}

The second theme includes reflections on how different spaces were used in different sessions according to the learning tasks that students were expected to do. For example, both teachers stated that the amount of time teachers spent with some teams could be considered for them as a proxy of the attention needed by those students. This is illustrated by the following reflection: "Some teams have not been frequented that much (pointing at the left-most experimental setups in Figure 7, D). But we can see that both teachers were actually up here with this team (signalling at A). Maybe these chaps needed a lot of assistance" (T1). 
T1 also mentioned that even if the teacher was not very close to certain teams, they could be observed from a longer distance. For example, T1 followed up his previous reflection as follows: "these chaps (at Point B) are sitting very close [to the team at A] so teachers could have actually watched what they were doing. Although they may not need much assistance, it doesn't necessarily mean they're being neglected". This reflection is very relevant for the design of interfaces that alert the teacher of potentially neglected groups of students (e.g. An, et al., 2018; Martinez-Maldonado, 2019). Other sources of evidence may need to be considered (e.g. body posture, head direction or gaze), before deciding if a team has been attended to.

Both teachers mentioned that they could see that positioning data were concentrated closer to the experimental settings for LD1 (e.g. Figure 7, C) and LD3 (Figure 7, H) than to the classes enacting LD2. T1 explained: "In the experiments (in LD3), you may notice that the dots should be close to the bench because there is the place where things are happening. With other experiments [for LD2], students do the work in other spaces also". T2 also gave meaning to some concentrations of data points according to the learning design, following the same rationale: "For [LD 2] it would be understandable having the teacher spending time away from the benches because some experiments are conducted on the floor". This was confirmed while the teacher inspected the map of session 7 (Figure 7, centre), explaining the concentrations of data points in Point G as follows: "I remember on this side of the classroom both teams were testing with the (floor) fan. So, if they need more room, they probably would move to the side and myself, and the other teacher had to be attending these teams from these positions". T2 summarised how he interpreted the 'blotches' in the maps for LD3 according to the learning design as follows: "If we have dots in the alley, it means just moving on or just supervising, not really explaining or attending. You or the other teacher need to be close to the bench because the experiment's happening at the bench".

Certain pieces of furniture associated with specific spaces in the classroom were used only during the enactment of LD2. These were some tables and the whiteboard. In the four classes in which LD2 was enacted (5-8) one or two teams of students set up their experiment on the large bench located next to one of the walls of the classroom (e.g. see Point E in Figure 7). This was a difference highlighted by T2 as follows: "Yes, we definitely use this extra bench only for LD2". This space was used by students whose experiment involved testing appliances such as large displays. Although they were allowed, students did not set up any experiment on the additional benches for LD1, and for LD3 these were set up by facilitators.

The use of the whiteboard was highlighted as another key difference across learning designs. $\mathrm{T} 1$ and T2 explained that, although formulas are used in the three kinds of tasks, the characteristics of the tasks and the kinds of outputs students need to produce, helped to explain the presence of teachers near the whiteboard, particularly in classes enacting LD2, and in LD3. T1 explained the following while signalling at Points F in Figure 7: "That is interesting. You see? This is prescriptive (LD1). Not much happens at the whiteboard in all cases. In the authentic task (LD2) where you wouldn't expect the teacher to do everything on a whiteboard maybe they are trying to explain many things. This is intriguing [as each team is doing a different project]. Whereas here (LD3) there's [not much] on the whiteboard, even though they do theory work". T2 reflected that the use of the whiteboard in LD2 is justified because of the kind of outputs students need to produce: "I probably went to explain what they had to do in the report. That is what they had to write in the report, using this formula". T1 explained that formulas are heavily used for LD3 but explained that perhaps the whiteboard is not being used much because "tutors come to the table and work with the students at the table on the paper because it's paperwork what they do". 
In sum, these reflections illustrate how the interpretation of positioning data is strongly shaped by the learning design. This includes not only the kind of tasks that students are intended to perform, but also practical issues such as the kinds of objects students interact with, the expected deliverables (e.g. a report), and the particular spaces in which learning is happening.

\subsubsection{Vignette 3: Differences between teaching assistants}

The third theme includes reflections highlighting differences about how assistants moved in the classroom across learning designs. These emerged while the teacher in the classroom (T2) noticed that the two sessions in which he taught the class with assistant T4, showed a particular pattern that was not present in the other ten sessions. This was articulated by T2 as follows: "In this one (pointing at the orange data points in session 2; Figure 8, centre). He (T4) is not giving that much help [to students]. That's the difference between the three assistants (pointing at maps of session 1, 3 and 4; Figure 8, left and right). They (T3 and T5) are giving academic help to the students, but that person is doing it differently".

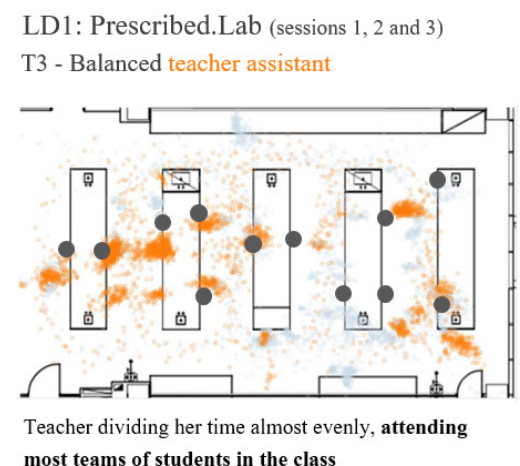

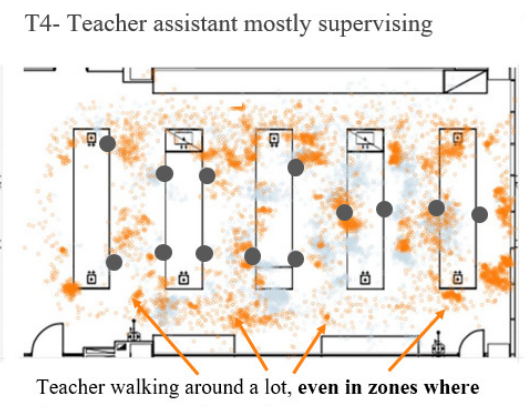

there are no experimental setups
T5 - Teacher assistant spending too much with students

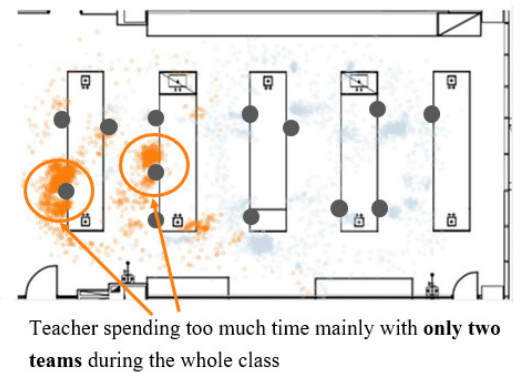

Figure 8. Three example maps in which the positioning data points of three different assistants are shown in orange featuring. Behaviours were assessed by $\mathrm{T} 2$ as i) balanced (T3, left); ii) supervisory (T4, centre); and iii) spoon-feeding (T5, right).

T2 reflected on the differences in the density of the data points to explain behaviours that each of his assistants featured during the classes. For example, in Figure 8 (left), the denser patches of T3's data are closer to 9 out of the 12 locations in which students installed their experiments. The teacher explained this is a 'balanced behaviour' because "the assistant is not concentrating on one group. She is giving help to everybody", which corresponds to the strategy he is expecting for them and for himself to follow. In contrast, the positioning behaviour displayed by T4 was considered inadequate in terms of supporting students. For example, Figure 8 (centre) was described by T2 as follows: "Surprisingly, he's going everywhere! I can tell from the way he is moving he is spending less time with students. I think T4 doesn't do much because the dark patches are few. His movement is more or less supervisory". The teacher later confirmed this behaviour was also observed in session 9, which was taught by the same assistant, even though it was a different learning design (LD3): "Like I said, he's spending too much time moving (pointing at session 9's map)'”.

T2 added that also spending too much time with certain teams is not recommended and he noticed this is a behaviour often featured by $\mathrm{T} 5$ in some classes, which was salient in the positioning data. In Figure 8 (right) T5's positioning data features only two large patches close to two experimental setups. The teacher reflected on this behaviour as follows: "Staying in one place for a long time is sometimes not good for the students. It's spoon-feeding. If you're genuinely asking something or you're giving background information, it may be okay. Otherwise, you are not letting students do their own work. This is especially important for [LD2 and LD3]". 
In sum, while certain patterns can potentially emerge as a result of looking at the data using a 'learning design lens', differences between teachers (with varying levels of teaching experience and expertise) can also explain the positioning data.

\subsubsection{Vignette 4: Temporality}

The fourth theme encapsulates reflections focused on how teachers' positioning varied as the class progressed. These emerged while teachers reflected on the positioning data divided into quartiles. Both teachers requested to see the positioning data of selected sessions, divided into quartiles, to contrast how the classes started or finished (e.g. attention was focused by both teachers on quartiles 1 and 2); or changed over time. T1 highlighted the benefit of looking at the more detailed information compared to the representation of the whole class, as follows: "These (pointing at the quartiles) can be better to compare than [the complete maps] because here it is harder to see differences of the class at the beginning".

Figure 9 shows teachers' positioning data points divided into quartiles (q1-4) for sessions 4, 7 and 11 that correspond to the enactment of learning designs LD1, LD2 and LD3, respectively.

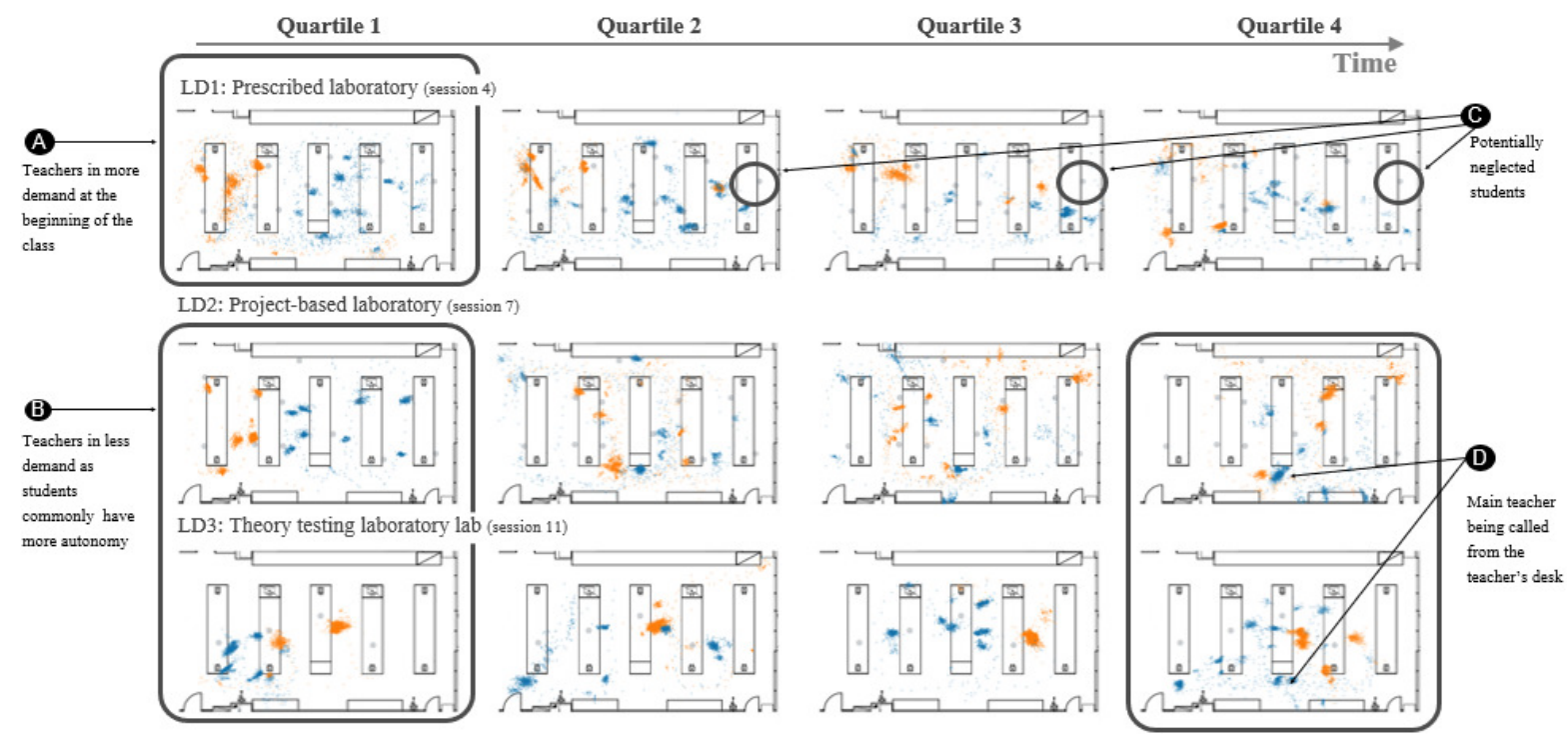

Figure 9. Maps in which the positioning data points of three classes (sessions 4, 7 and 11) were divided into four quartiles of the same length (Quartiles 1-4).

Teachers made sure the durations of classes were similar (2.20, 2.30 and 2.30 hours). Both teachers reflected on how at the beginning of the prescribed labs (LD1) teachers commonly showed a different behaviour compared to classes enacting LD2 and LD3. T1 expressed this as follows:

"because it's a prescribed experiment, students commonly expect everything to be prescribed. So, they ask teachers to come and they ask for every little tiny thing [written] in the lab manual". The teacher pointed to Figure 9 (A) to show how teachers moved back and forth from the teacher's computer position to where teams set up their experiments. By contrast, T1 mentioned that "LD2 and LD3 are more similar in terms of authenticity, as teachers do not move much at the beginning. The facilitator gets small questions asked but they would simply say 'think about it' (pointing at Figure 9, B)". This highlights the potential of exploring certain patterns that can emerge at the beginning of the class based on the expected dynamics of the class defined by the learning design.

T2 reflected how one of his assistants stayed with the same two teams of students for half of the class, noting the teacher should have moved to attend other students as well. This was phrased as 
follows: "The orange patch stays in the same place, at least until halfway. The blue patch seems to be moving to different teams (pointing at the first two quartiles Session 4)". This made the teacher also reflect on when in the class the least attended teams of students may have been. For example, T2 pointed at the team in Figure 9 (Points C) across all the quartiles to reflect on when in the class this group may have been checked by himself. Then, the teacher reflected as follows: "Probably, in the first quarter they got some help. I may have looked at them across the bench in the third quartile too".

Finally, both teachers reflected on how, for LD2 and LD3, teachers tended to deal with more unexpected events towards the end of the classes. For example, T1 pointed at the quartiles marked in Figure 9 (D, LD2 and LD3) while reflecting as follows: "By the end of these classes, it is not like teachers walked around benches one by one, along a certain path. It is commonly unsynchronised because many students come over and ask for attention". T2 added: "Teachers are in much more urgent demand going from one place to the other [by the end of LD2 and LD3]. In sum, these reflections highlight the importance of teachers to also reflect on positioning data in relation to temporality aspects of the class.

\subsection{Metrics for classroom positioning data}

This section presents the prototype metrics for classroom positioning that were designed based on teacher's reflections, the characteristics of the learning designs of the study and relevant literature. Each metric is motivated, defined, and formally operationalised. T1's responses to these metrics are then reported and discussed.

\subsubsection{Metrics related to teacher's stops}

Motivation. T1's immediate reaction on inspecting the positioning data of his teachers for the first time was: "what jumps into my eye, is the number of colour 'blotches' on the paper", referring to the concentrations of data points. These were interpreted with expressions such as "the teacher lingers" (T1) or to assess whether a teacher is "staying in one place" or "just walking around" (T2).

Definition. A teacher's stop can be defined as a sequence of data points that are very close in time and space, denoting a period in which the teacher is, for example, attending students, sitting at her desk, using the whiteboard, or just staying in one place surveying the classroom.

Figure 10. Parameters to define a teacher's stop

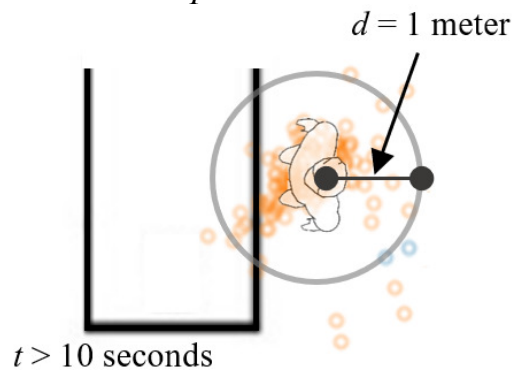

Table 2. Metrics related to teachers' stops. Values correspond to the accumulated metrics for both teachers in terms of i) number of stops, ii) total stopping time, iii) time per stop and iv) longest stops $(a v g \pm s t d)$. Higher values per row highlighted in shades of green.

\begin{tabular}{llll}
\multicolumn{1}{c}{ Learning design $\boldsymbol{V}$} & \multicolumn{1}{c}{ LD1 } & \multicolumn{1}{c}{ LD2 } & \multicolumn{1}{c}{ LD3 } \\
\hline \hline Summary of both teachers $\boldsymbol{\nabla}$ & & & \\
i) Number of stops & $151 \pm 26$ & $131 \pm 16$ & $118 \pm 19$ \\
ii) Stopping time (min) & $217 \pm 27$ & $239 \pm 19$ & $252 \pm 15$ \\
iii) Time per stop (min) & $1.5 \pm 0.2$ & $1.9 \pm 0.3$ & $2.2 \pm 0.4$ \\
iv) Longest stop (min) & $13 \pm 3$ & $18 \pm 1$ & $24 \pm 8$ \\
\hline
\end{tabular}

Calculation. Positioning data points can be modelled as a stop by clustering them based on two parameters. The first, parameter $d$, is the maximum distance from a data point and the (current) centroid of the stop to be considered part of the stop. Data points can be iteratively added to the stop data structure, and the centroid is recalculated each round. The second, parameter $t$, is the minimum time for a cluster of consecutive data points to be considered a stop. In our study, we used $d=1$ meter 
based on a heuristic reported in the literature to consider teachers' personal space (Sousa et al., 2016); and $t=10$ seconds. This means a stop was considered for those moments in which a teacher lingered in a certain position within a moving radius of 1 meter for more than 10 seconds (Figure 10). From this construct, other metrics can be calculated, such as total or partial number of stops or average stopping time; or more complex metrics in relation to other sources of evidence, such as student locations.

Results. Table 2 summarises (i) the average number of stops, (ii) total stopping time, (iii) time per stop and (iv) the longest stop for both teachers in each class, grouped by learning design. Detailed summaries per teacher were also provided to $\mathrm{T} 1$ to register his reactions to these metrics and the ones in the subsections below. Overall, the LD1 sessions showed more variability in the number of stops (teachers averaged $151 \pm 26$ stops in the classroom, Table $2, i)$ in comparison to LD2 (131 \pm 16$)$ and LD3 (118 \pm 19$)$. T1 explained this as follows: "In the prescribed tasks (LD1), the number [of stops] is high. That means that teachers are moving to different sections more often. Teachers are sort of stopping a lot".

Stops for LD3 were less numerous and longer (see column LD3), with the longest stops averaging up to $24 \pm 8$ minutes (against $13 \pm 3$ and $18 \pm 1$ minutes, for LD1 and LD2). These metrics confirm the explanations by teachers presented in the previous section. The differences in learning designs can strongly explain the way teachers positioned themselves in the classroom. T1 explained: "For the theory verification task (LD3) the metrics show what I expected. We had experiments set up as demonstrations, which only the teachers were allowed to execute. This means, they had to be there and provide longer explanations. These longer [stops] mean the teachers had to be at those locations". The teacher did not have a strong view regarding metrics for LD2.

\subsubsection{Metrics related to teachers' transitions}

Motivation. This is the second basic construct that can be used to calculate other positioning metrics. For example, while inspecting the visual representations of his teachers' positioning data, reported in the previous section, T1 reflected as follows: "so if I look at the separation of the dots, does this tell me something about the speed how they go through the trajectory?".

Definition. A teacher's transition can be defined as a sequence of positioning data points that follow a trajectory between two stops to model those moments when the teacher is, for example, walking from attending one team to another, walking around supervising the whole class, or moving towards a specific zone of the classroom.

Calculation. In this study, data points which were temporally between two stops were grouped into a transition (hence the two parameters $d$ and $t$ are also relevant). Although a smoothing (moving average) algorithm is used by the sensing software when capturing positioning data, each data point is an estimate (with its associated error) of the actual position at any given time. Thus, the teacher's trajectories were modelled using the linear quadratic estimation algorithm (also known as Kalman filtering) which has been implemented in indoor positioning solutions in the field of geo-information (Wang et al., 2015) All data points between two stops were grouped, including the centroids of these, to optimise the modelling of teachers' trajectories between stops (see Figure 11). From this basic construct, other metrics can be calculated, such as the distance walked by the teacher, their speed and acceleration, and the transitions between specific groups of students or classroom spaces.

Results. Table 3 summarises ( $i$ ) the averaged number of transitions, (ii) total distance walked, and (iii) walking speed for both teachers in each class, grouped by learning design. In this case, the metrics are more similar for teachers enacting LD1 and LD2, particularly for the distance walked (ii). The learning designer (T1) reflected on this as follows: "We have obviously fewer transitions for 
[LD3], for the last four sessions. In a way, transitions are the opposite to [the concept of a stop]" (see Table 3, column LD3).
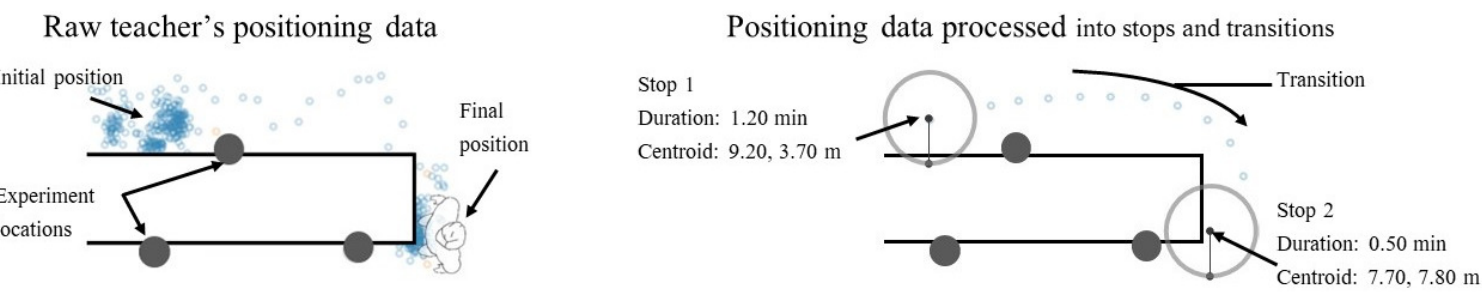

Figure 11. Left: Unprocessed teacher's positioning data points. Right: Processed teacher's trajectory after applying the Kalman filter to data points between two stops.

By contrast, teachers enacting LD3 tended to move somewhat faster (see Table 3, row iii). This was explained by T1 as follows: "what it commonly happens in [LD3] is that [teachers] are more like sort of a fire brigade. Something goes wrong here, and there goes a hand up here, [something is needed there] and there goes a hand up there. They can sort of end up running all over the place". This suggests that the way in which transitions were modelled may also help the teacher to reflect on teachers' differences and identify outliers that may point at unexpected teacher's behaviours.

Table 3. Metrics related to teachers' transitions, grouped by learning design. Values correspond to the accumulated metrics for both teachers in terms of i) number of transitions between two stops, ii) total distance walked, and iii) teacher's estimated speed ( $a v g \pm s t d)$.

\begin{tabular}{cccc}
\multicolumn{1}{c}{ Learning design } & LD1 & LD2 & LD3 \\
\hline \hline Summary of both teachers $\boldsymbol{\nabla}$ & AVG & AVG & AVG \\
i) Number of transitions & $151 \pm 26$ & $129 \pm 16$ & $117 \pm 18$ \\
ii) Distance walked $(\mathrm{km})$ & $1.9 \pm 0.2$ & $1.9 \pm 0.3$ & $1.7 \pm 0.5$ \\
iii) Walking speed $(\mathrm{m} / \mathrm{s})$ & $0.8 \pm 0.1$ & $0.9 \pm 0.1$ & $1.0 \pm 0.1$ \\
\hline
\end{tabular}

\subsubsection{Metrics related to the interactional space of students}

Motivation. Some of the teacher's stops can be associated with certain meanings. For example, if a stop happened near where students are (or where they are expected to be) teachers in our studies mentioned that this could be used to estimate "the frequency to which students were attended by the teacher" (T2) or the "time that the teacher actually spent with particular students" (T1).

Definition. According to Lim, et al. (2012), the interactional space in the classroom is realised when the teacher stands in close proximity to individuals or groups of students, especially during learning activities. In this space, the teacher can reduce the interpersonal distance to offer guidance on the task or invite students to clarify any uncertainty. Authors suggested that the interactional space may be shaped by the classroom space, the type of learning task and individual characteristics. Work on proxemics has defined that a maximum distance from 0.75 to 1.20 meters ( 2.5 to 4 feet), depending on the angle of the body, can define the space in which people can socially interact (Martinec, 2001).

Calculation. A teacher's stop can be happening within the interactional space of a team of students if this was within a certain interactional distance (idis). In our study, we considered idis $=1$ meter (or 3.23 feet, based on the heuristic aforementioned). From this construct, other metrics can be calculated, such as the estimated attention time per student, frequency and duration of visits, and sequencing.

Results and learning designer's reflection: In this study, the focus was on analysing teachers' proximity to students' experiments. For LD1 and LD2, these can be associated with where teams 
lingered. For LD3, teams moved from one experiment to another. Thus, the locations of the experiments are not proxying students' positions. Table 4 summarises $(i)$ the averaged accumulated time that teachers spent in close proximity to students' experiments, (ii) the total number of times they visited any experiment, (iii) the duration of attention per experiment and (iv) the number of visits per experiment. T1 reflected: "we have more visits for the prescribed [LD]" (see Table 4, rows $i$ and $i i$ ). For LD1 teachers averaged $130 \pm 21$ visits to experiments, spending a total of $190 \pm 21$ minutes near experimental setups. T1 explained that this confirms what he expected: when the students get the task prescribed, they become more dependent of teacher's input. This was explained as follows: "So that data [rows $i$ and ii, column LDI] reflect what I wrote in my [reflective report] after interpreting the dots. It looks like the teacher had to spend more time with the students to explain to them what has already been explained in the manual. Students tend to be asking for confirmation for every single step, many steps then add up to a lot of teachers' time".

Table 4. Metrics related to the interactional space of students. Values correspond to the accumulated metrics for both teachers in terms of i) attention time to experiments, ii) number of visits to experiments, iii) attention time per experiment and iv) number of visits per experiment ( $\mathrm{vvg} \pm s t d$ ).

\begin{tabular}{lrrr}
\multicolumn{1}{c}{ Learning design } & \multicolumn{1}{c}{ LD1 } & \multicolumn{1}{c}{ LD2 } & \multicolumn{1}{c}{ LD3 } \\
\hline \hline Average of both teachers $\boldsymbol{\nabla}$ & & & \\
i) Attention time to experiments/teams (min) & $190 \pm 21$ & $165 \pm 13$ & $144 \pm 37$ \\
ii) Number of visits to experiments & $130 \pm 21$ & $100 \pm 11$ & $73 \pm 5$ \\
iii) Duration of attention per experiment (min) & $15 \pm 2$ & $14 \pm 2$ & $36 \pm 9$ \\
iv) Number of visits per experiment & $10.5 \pm 2$ & $8.5 \pm 1$ & $18.3 \pm 1$ \\
\hline
\end{tabular}

The metrics in rows iii and $i v$ model for the teacher "how equal the attention was spread across all the teams, so if the deviation is high, then there was a sort of a big spread" (T1). T1 explained that for LD1, the low standard deviation is expected "because all the teams receive similar attention, you know, from 8 to 11 visits, so if I have a standard deviation of one that would be kind of ideal?". However, the teacher mentioned his belief about what would have occurred for LD2 was contradicted by the evidence. The values for LD2 (rows iii and iv) are very similar to those of LD1 with similar standard deviations. T1 reflected on this mismatch between his hypothesis and the data as follows: "For LD2, what every [team] is doing is entirely different. It requires a totally different approach by teachers for what the students do so the attention cannot be sort of uniform. Having said that, we should see something different in week two. This doesn't really happen up there for [LD2]".

Finally, T1 confirmed that for LD3, teachers actually spend time differently for each of the experiments they need to run for students to reflect on since "the equipment is more complicated for some experiments" and "students typically approach the teacher, for teachers to go around and help fixing things [with the four experiments]".

In sum, this suggests that contextual information to the notion of teacher's stops shifted the reflection of the teacher to a higher level, for example, by mentioning the spread of teacher's attention and potential mobility strategies.

\subsubsection{Metrics related to classroom spaces of interest}

Motivation. Besides the places where students are, some classroom spaces may be meaningful because of the presence of certain objects or the activities that occur in them (e.g. as discussed in Section 5.1.2, in terms of teachers' reflection about the use of the teacher's desk or the whiteboard). 
Definition. Each classroom space may have fixed spaces or objects that may give meaning to teachers' positioning data. The close proximity to or the presence of the teacher in those spaces may facilitate the sense-making of such data.

Calculation. In this study, teachers' proximity to specific objects in the classroom was modelled as positioning data points within a certain distance to a space of interest (dSoI=1 meter). Four spaces of interest were mentioned in teachers' reflections corresponding to the teacher's desk, the whiteboard and the two tables that teachers commonly used to do paperwork or organise students' outputs from previous tasks (see Figure 2). Alternatively, spaces of interest can be mapped on the floor map to detect whether a teacher was present in a specific space. For example, positioning trackers could be installed on moveable objects to configure adaptable spaces of interest. In this study, all spaces of interest were fixed.

Results. Table 5 summarises the averaged accumulated time that teachers spent near the teacher's desk where the computer that controls the screens is located $(i, i i)$, the whiteboard (iii, iv) and the regular tables $(v, v i)$. In terms of the presence of teachers near their desk, this is very low for both teachers enacting LD1. For example, the main teacher averaged $14 \pm 3$ minutes in his desk for LD1 and $51 \pm 7$ and $49 \pm 11$ minutes for LD2 and LD3 (row $i$ ). T1 reflected on this as follows: "He doesn't have time to hang around the computer because he's requested at the experiments [LD1]. Whereas when we send students off to do their own work [LD2 and LD3] he has more time to stay in his own space".

Table 5. Metrics related to spaces of interest by learning design. Values correspond to the accumulated time teachers spent in close proximity to i-ii) the teacher's computer, iii-iv) the whiteboard, and v-vi) regular benches ( $a v g \pm s t d)$.

Learning design

LD1

LD2

LD3

\begin{tabular}{lrrrr}
\hline \hline Summary of both teachers $\boldsymbol{\nabla}$ & & & \\
i) Main teacher at teacher's desk (min) & $14 \pm 3$ & $51 \pm 7$ & $49 \pm 11$ \\
ii) Assistant at teacher's desk (min) & $0.2 \pm 0.4$ & $5 \pm 4$ & $8 \pm 5$ \\
\hline iii) Main teacher at whiteboard (min) & $0.4 \pm 0.4$ & $1 \pm 1$ & $3 \pm 1$ \\
iv) Assistant at whiteboard (min) & $2.2 \pm 1$ & $1.4 \pm 1$ & $3 \pm 2$ \\
\hline v) Main teacher at regular tables (min) & $5.6 \pm 3$ & $7.3 \pm 6$ & $10.8 \pm 8$ \\
vi) Assistant at regular tables (min) & $4.0 \pm 2$ & $7.6 \pm 6$ & $35.2 \pm 19$ \\
\hline
\end{tabular}

When teachers inspected the positioning datapoints, T1 mentioned that the whiteboard had been used mostly in classes enacting LD2 (see section 5.1.2). However, after looking at the actual proximity metrics in relation to the whiteboard (rows iii and $i v$ ) teachers in LD3 actually spent more time near the dashboard, possibly giving explanations on modelling formulas, averaging $3 \pm 1.5$ minutes per teacher in each class. T1 reacted to this as follows: "now I can see there is some considerable time spent at the whiteboard. But still it doesn't happen for [LD1] much. It mostly happens for the theory experiment [LD3] where the teacher tries to show students whether their idea might be on the right track or not".

Finally, the regular tables were used primarily for the classes enacting LD3. T1 explained their use in terms of learning tasks performed online. In this case, students had received feedback about submitted reports and they were seeking feedback from teachers: "this can be explained because, in this week, students had gotten their marks. Could be a case like students come and said okay I submitted a report and I don't quite understand why I got low marks. So, the teacher has to go through their reports". 


\subsubsection{Metrics related to co-teaching}

Motivation: The study presented in this paper is an example of in-classroom collaborative teaching (or co-teaching) which can add complexity to the way a learning design is delivered and the skills needed by teachers to work effectively (Friend et al., 2015). In the study, the learning designer was interested in knowing the times in which both teachers were together.

Definition: An instance of proximity between two teachers can be defined for moments in which the distance between each other is within their respective interactional spaces.

Calculation: Instances when the main teacher and the assistant went very close to each other were identified according to the parameter $d$ Teacher (1 meter for consistency with other metrics). Further information could be obtained from the context of such instances such as whether both teachers were in a space of interest, near a group of students, when in the class it happened, and the rotation of their bodies.

Results: Table 6 summarises the time both teachers got together during the classes. The classes in which LD2 was enacted (and LD1 to a lesser extent) were the ones in which teachers got together more often ( $3.3 \pm 1$ and $4.5 \pm 2$ times). Classes in which LD3 was enacted only averaged 1.8 \pm 0.4 times when teachers were close to each other. The teacher explained that he could "distinguish unique types of dynamics within the classroom" because teachers need to coordinate how they will deliver the class and help the students. LD1 and LD2 require teachers a greater extent of coordination since they need to be aware of the progress of 10-14 teams at the same time. For LD2, each team is doing a different project. This means both teachers could be attending the same team if the degree of sophistication of an experiment was high. By contrast, for LD3, two teachers needed to act as demonstrators of four experiments. Hence it makes sense for teachers to avoid redundancy by not being together in the same experiment.

Table 6. Number of times teachers got together grouped by learning design.

\begin{tabular}{cccc} 
Learning design & LD1 & LD2 & LD3 \\
\hline \hline i) Times teachers got together & $3.3 \pm 1$ & $4.5 \pm 2$ & $1.8 \pm 0.4$ \\
\hline
\end{tabular}

\subsection{Teachers' reflections in terms of translucence and orchestration}

This subsection presents reflections externalised by teachers during the post hoc interviews. Questions asked were organised according to the three principles underpinning "translucent design" as introduced earlier (Prestigiacomo, et al., 2020), namely, visibility, awareness, and accountability.

\subsubsection{Visibility: what is made visible through positioning data?}

Teachers appreciated the opportunity to inspect the data and think about how these reflected their expectations according to the learning designs and the classroom experience. T2 explained that, in his whole teaching experience, he had never seen his positioning patterns accurately recorded this way. This was stated as follows: "Actually, it is the first time I've seen this kind of thing. It is really good because you see the real situation. I see the things I didn't see during my time in the class. Definitely, yes, I think it is helpful".

T1 identified patterns that might be candidates for 'classroom proxemic metrics'. He particularly contrasted how teachers commonly react to students' activity for LD1 and LD2. For LD1, teachers may organise themselves in the classroom, attending one team after the other since all are performing the same task. This was expressed by $\mathrm{T} 1$ as follows: "By looking at the data, we identified this staccato style type of scattering [for LD1]". By contrast, the teacher referred to the less uniform positioning distribution of teachers as a result of students' task diversity in LD2, and a much more concentrated distribution of teachers for LD3. This was explained as follows: "[in LD3] positioning is 
a lot more concentrated. If this qualitative blur [in LD2], how I call these things, can be quantified, that would be quite interesting".

Finally, T2 explained the potential of making these data available to see things that are very hard to see and reflect on while the class is happening: "I didn't see it. Now I see it. That's the one good thing that's come out of this total picture". He also explained that the data can help him identify hot spots in the classroom, reflect on inequality of attention provided to students and think about better ways to coordinate co-teaching with his assistants: "I didn't see that I spend more time in one place. My expectation would be that I spend time everywhere. Not equally, but at least not this much concentration in one place and not much in other important places. At least, the assistant and myself should handle things better".

\subsubsection{Awareness: what to do with these data?}

T1 highlighted the potential of identifying unwanted patterns that could be addressed by making changes in the learning design. T1 explained that positioning data could be helpful for "explaining to [the teachers who will enact the learning design] the expected dynamics of the class and how other teachers have worked". T1 explained how his own reflections were pointing already at considering changes in the current designs. This was elaborated as follows: "For instance, this one (LD1), students need continuous incremental attention to run the prescribed experiments. We have to find a pedagogy to remedy that".

$\mathrm{T} 1$ added that these data could also be useful for professional development, especially for teaching assistants who commonly lack formal pedagogical training. T1 suggested how positioning representations could complement peer-observations or serve in the induction of new assistants, as follows: "Observing the laboratory class dynamics would be interesting to them. [These data] could help to train new tutors and also current staff". T2 added that the induction should be guided by someone with experience in teaching the same classes to explain the meaning of the data: "when I get a new assistant next time, we must give him some induction. This is the real data. I think if somebody should show to new tutors these results and explain when there is a pattern". This suggests further work is needed to find patterns over longitudinal studies and explore how interventions can support teaching improvement.

Finally, both teachers mentioned that the main teacher could use this data to reflect on particular classes. T1 expressed that "mostly T2 should look at these data because he is managing the class and is responsible for the approach". T2 indicated that using these data "straight after the class" would be useful to improve the next classes. $\mathrm{T} 2$ also saw value in these data even though he is very experienced in enacting these learning designs. This was expressed as follows: "I have done these classes for so many years. But I didn't quite realise all these kinds of things were actually going on between my assistants and myself. Even it can happen you miss a team during the whole class".

\subsubsection{Accountability: what are the implications of showing these data to others?}

In the teachers' reflections, there was a clear intention to let other stakeholders see the kind of data captured in authentic university classrooms. T2 initially stated: "I think everybody should look at it! The other teaching members, especially". However, this raises ethical and operational implications that should be considered in the design of classroom positioning innovations in the future. For example, the interest of some stakeholders in looking at the data is clear. The learning designer justified his interest as follows: "Because I'm not staying in the laboratory class myself, [these data] is something that I would be interested in seeing and for facilitators to think about. I did this kind of class myself!'. Teachers also explained that staff at the division of teaching and learning of the 
university would be interested in "using this evidence to train new tutors and staff" (T1) and also to "optimise the learning spaces" (T2).

However, teachers also warned that potential uses of the data should be clearly defined and that certain mechanisms should be put into place so that the teachers being observed are aware of the use of their data. For example, positioning data should not be used to assess individual performance, unless other sources of evidence are included. T1 explained that the data could be used to support some sort of assessment of the classes but warned that "the kinematics cannot tell us very much about the performance of the tutors". He pointed at examples in which some anomalies could be easily detected. T1 referred to the differences between assistants (discussed in depth by T2 in Vignette 3 in Section 5.1.3) as follows: "Here we see a very well geared tutor and assistant relationship (pointing at sessions 1, 3 and 4). Teachers seem to have a strategy that works, they divide [the classroom] up, and it's well organised. I know occasionally I have an assistant that would just sit in the corner bench just googling on their mobile phone and do nothing". This kind of pattern would be picked by the location sensors, paired with other sources of evidence. T2 explained that it would be fine to detect this kind of behaviours, but to implement strategies that are not punitive, for example, the assistants could "get feedback on their performance for improvement" or participate in a "[guided] reflection, not in an intimidating way, not assessing the person but on how to improve the class outcome".

Teachers also emphasised the risks of students seeing these data. T2 stated: "students will complain, especially if they didn't get any help. But this is a good point. If I had that data [in time], perhaps I could bring those students back somehow to do the job". Both teachers explained that this and other risks of interpretation might exist without considering further sources of evidence to make strong claims about the classes. In terms of assessment of teaching assistants, for example, T1 warned that the lack of engagement with students may not always be negative: "it might as well be that one of the tutors is sticking to a bench for 20 minutes because there's nothing else to do, for example, because students need to be looking at a microscope for a long time”.

In sum, teachers highlighted the potential of these visualisations to support reflection, but they mentioned that the lessons learnt from their own analysis could not be generalised. T1 explained: "I'm not sure [results from this analysis] can be generalised. For my class you can say, it is alright right finding my teachers bunched up in a corner, that just tells me what I've seen [in LD3] but not for others". This foregrounds the importance of the context of the activity for interpreting positioning data which, in this case, was strongly tied to the learning tasks. T2 also highlighted the need for "positioning data to be coupled with other sources of evidence" to provide effective feedback to teachers on classroom proxemics.

\section{Discussion}

This section discusses how our initial research questions (RQs 1 and 2) were addressed through the results (presented in Sections 5.1 and 5.3, and 5.2 respectively), and implications and limitations of the study presented in this paper.

\subsection{Comparing teachers' preconceptions and positioning data metrics}

We identified from the interview data several tensions between teachers' preconceptions of what is supposed to happen and what actually happened in the classroom. Table 7 summarises the metrics and the insights that emerged from the study.

The main tension resulted from the learning designer's expectation that teachers' behaviour would be similar for classes in which LD2 and LD3 were enacted, given that both activities were intended to be "authentic", featuring much more complexity than the prescribed task (LD1). 
Certainly, some aspects were similar between the enactments of LD2 and LD3, such as teachers being in less demand at the beginning of the class, and finishing the class moving more frequently (Vignette 1 on Temporality, Section 5.1.4). However, they also remained longer near the teacher's desk (which is often related to the personal space according to the notion of spatial pedagogy; see Table 7,iv).

However, some metrics suggested that, in fact, LD1 and LD2 shared more similarities, with all teams receiving a similar amount of attention (Table 7, iii), even though the frequency and length of visits may have been different (Table 7, $i$ and $i$ ), and both teachers had to come closer to each other while each team of students performed the experiments (Table $7, v)$.

Table 7. Metrics for classroom proxemics.

\begin{tabular}{|c|c|c|}
\hline Metric type & Metrics calculated & Insights \\
\hline \multicolumn{3}{|l|}{ Metrics related to.... } \\
\hline i) Teacher's stops & $\begin{array}{l}\text { Number of stops } \\
\text { Time teachers remained in stop } \\
\text { Time per stop } \\
\text { Longest stop }\end{array}$ & $\begin{array}{l}\text { - For LD1, teachers' stops were more numerous, and variability was } \\
\text { higher } \\
\text { - For LD3, stops were less numerous and longer } \\
\text { - The longest stops were in LD3 }\end{array}$ \\
\hline $\begin{array}{l}\text { ii) Teacher's } \\
\text { transitions }\end{array}$ & $\begin{array}{l}\text { Number of transitions } \\
\text { Distance walked } \\
\text { Walking speed }\end{array}$ & $\begin{array}{l}\text { - For LD1, teacher's transitions were more numerous } \\
\text { - For LD1, and LD2 the distance walked was longer and quite similar } \\
\text { - For LD3, the walking speed was faster }\end{array}$ \\
\hline $\begin{array}{l}\text { iii) Students' } \\
\text { interactional space }\end{array}$ & $\begin{array}{l}\text { Attention time to all students } \\
\text { Number of visits to all students } \\
\text { Attention time per student/team } \\
\text { Number of visits per student/team }\end{array}$ & $\begin{array}{l}\text { - For LD1, the total time spent by teachers' attention } \\
\text { students/experiments was higher than LD2 and LD3 } \\
\text { - For LD1 and LD2, the attention received by each team from both } \\
\text { teachers was quite similar (egalitarian) to other teams } \\
\text { - For LD3, the teacher remained at experiments twice the time than in } \\
\text { LD1 and LD2 }\end{array}$ \\
\hline $\begin{array}{l}\text { iv) Classroom spaces } \\
\text { of interest }\end{array}$ & $\begin{array}{l}\text { Teachers' time at/visits to: } \\
\text { the teacher's desk } \\
\text { the whiteboard } \\
\text { regular benches }\end{array}$ & $\begin{array}{l}\text { - For LD2 and LD3, teachers remained around } 50 \text { minutes near the } \\
\text { teacher's desk compared to } 15 \text { minutes for LD1 } \\
\text { - The whiteboard was used in LD3 and, to a lesser extent, in LD1 and } \\
\text { LD2 } \\
\text { - Regular benches were intensively visited by teachers for LD3 }\end{array}$ \\
\hline v) Co-teaching & $\begin{array}{l}\text { Number of times teachers got } \\
\text { together }\end{array}$ & $\begin{array}{l}\text { - Teachers got together more frequently in LD2, and LD1 to a lesser } \\
\text { extent }\end{array}$ \\
\hline
\end{tabular}

Looking at their reflections, the key message from this teacher inquiry loop is that positioning data allowed teachers to think about what makes each learning design distinctive, instead of trying to find equivalence between them. This was highlighted in the first two themes related to territoriality (Vignette 1, Section 5.1.1) and how different spaces were more or less relevant for particular learning designs (Vignette 2, Section 5.1.2). The data also provoked reflection on the behaviours of assistants, highlighting the presence of an assistant who engaged little with students (Vignette 3, Section 5.1.3; and Table $7, i v)$. Teachers also valued the opportunities for deeper reflection on non-aggregated data such as the datapoints being presented in quartiles (Vignette 4, Section 5.1.4), although the amount of information they had to process is evidently higher.

Finally, some design implications can be derived from teacher's reflections, particularly when questioned about accountability aspects to be considered. Different stakeholders may be interested in using these data, particularly for professional development, to warn teachers in class, to improve the use of learning spaces or for training new teachers. However, they also warned against potential misuse if other sources of evidence are not considered, particularly if the intention is assessing teachers' performance. Careful attention should be paid in generating mechanisms to avoid such unintended uses of the data. 


\subsection{Implications and future work}

\subsubsection{The role of the learning design to make sense of classroom proxemics}

It is not surprising in the study presented in this paper that teachers referred to the learning designs to provide the context for making sense of low-level positioning data (Lockyer et al., 2013). Although these classes had been taught by several different teachers of varied experience, the coordinator had observed consistent differentiating behaviours. For designers of classroom innovations willing to use positioning data, the reflections and the metrics presented here can serve as guidance to strongly shape the design of the interfaces based on aspects of the learning design. An early alert to this principle was identified in a pilot study (Martinez-Maldonado, 2019) in which the teacher questioned the validity of an alerting interface designed with the assumption that the teacher would be circulating from one group to another. For other collaboration patterns, such as a poster presentation, this assumption does not hold. In sum, we can hardly envisage a one-size-fits-all interface that fits different learning designs, as it has been attempted in previous works (An et al., 2020; An, et al., 2018; Martinez-Maldonado, 2019). The challenge can be summarised as follows: how do we design visual representations of positioning data that consider (i) contextual information, such as the learning design, along with (ii) particular characteristics of the classroom (e.g. furniture arrangements and the interior design) and (iii) temporality aspects?

\subsubsection{Potential risks of over-interpretation}

Although this work was focused on exploring teachers' reflections on low-level positioning data, without making any strong design commitment in terms of a particular visual representation, the teachers in the study often jump to conclusions prematurely based on a small number of classes provided to them from the whole set. For example, this occurred mainly for the learning designer who was not present in the classes. He would make a small selection from one or two sessions for each learning design and generalise from these particular patterns. However, these patterns were often not present in some of the unsighted instances (e.g. see results presented in Sections 5.1.1 and 5.1.2). Although bias in the interpretation of educational data is a general challenge in learning analytics (Slade \& Prinsloo, 2013), this brings implications for the design of further visual representations and the definition of the use of positioning data to warn stakeholders against the mistake of seeing important differences where none exist. It may be possible in the future to use automated metrics to help identify the prevalence of a given pattern in the dataset, to draw attention to areas of interest, and to assist in drawing more robust conclusions.

\subsubsection{Potential for speeding up analysis and the development of new proxemics theory}

The use of fine-grained teachers' positioning data automatically captured via sensors can speed up the analysis of teaching and learning in classroom spaces. For example, positioning information and evidence related to material or architectural aspects of the classroom could be used to enrich the analysis of social, epistemic and affective aspects to develop an ecological perspective on learning spaces (Damsa \& Jornet, 2016). Classroom observations of teachers' and students' movements and positioning patterns have conventionally been manually collected to identify why certain classrooms fail to meet educational needs (Scott-Webber et al., 2000). The use of positioning sensors could release human observers from logging where the teacher or certain students are, to focus on higher order constructs that add more complex layers of meaning to the positioning information. The metrics that emerged as a result of this study should be considered as an initial set of metrics of many more that can be generated to propose a quantitative approximation that could speed up the analysis of 
classroom proxemics (McArthur, 2008), spatial pedagogy (Lim, et al., 2012) or the assessment of architectural issues of the learning environments (Imms et al., 2016).

\subsubsection{Opportunities to support professional development}

This study has illustrated the potential for learning designers to consider changes in their learning designs if certain classroom dynamics do not emerge as expected. This was made evident by the learning designer who considered that the learning designs could promote certain kinds of teacherstudent relationships (e.g. it appeared that students required more frequent visits for LD1 than LD2). Moreover, the positioning data can provide evidence to assist in the process of designing for the learning space or motivating certain space arrangements (Bligh, 2014). Although only one classroom was analysed in this paper, a potential avenue of research could explore how the same learning design is enacted in different learning spaces, to explain the impact of the characteristics of the space on the activity. Additionally, research has found that it is expected that, as students improve, the distance between teacher and the student should increase (Koh \& Frick, 2009; Munro \& Stafford, 2012). The use of positioning sensors could provide evidence for teachers to reflect on improvement and how they approach students over time.

In terms of presenting positioning data to different stakeholders, the use of floorplans may be acceptable for exploration. However, these representations are at present too under-developed to serve as interfaces that can reliably communicate insights, without reference to complementary sources of knowledge. Positioning data can be quickly stripped of their context and meaning. In their reflections, teachers always used their first-hand class or learning design knowledge to interpret the data. This suggests other sources of evidence are needed to create meaningful interfaces for classroom proxemics. This introduces trade-offs, however: generating more data, increasing the complexity for their modelling, user interface design and interpretation, and an increasingly complex classroom setup.

\subsubsection{Limitations}

There are several limitations to this study. The main limitation is the number of classes observed and the number of teachers involved. This was due to constraints of time and availability imposed by the authenticity of the classroom conditions. Although future work should consider the inclusion of other teachers' and stakeholders' perspectives, results from this study are to our knowledge the first to shed light on teachers' reflections on low-level positioning data and related metrics. For example, we are making inroads into co-designing positioning-based interfaces with educators and students in healthcare education and training settings (Echeverria et al., 2019; Martinez-Maldonado et al., 2020b). Similarly, an analysis of the significance of the metrics obtained per learning design was not within the scope of the qualitative analysis of this paper. With a larger dataset it could be possible to mine the positioning data to identify patterns that could be used to differentiate teaching behaviours. Moreover, the segmentation of the data within a phase into quartiles was somewhat arbitrary, to enable the teachers to look at temporal aspects of their positioning. However, future work could explore more meaningful ways to segment the data, based on contextual information such as the task progress, or critical events in the classroom. Finally, the parameters used to calculate the metrics in the study could have been calibrated to respond to the particularities of the learning designs. For example, T2 mentioned that a teacher standing in the corridor for LD2 might mean that they are attending to a group, whilst this would mean "something else" for LD1 and LD3. This points to the opportunity to generate learning design-aware classroom positioning metrics. 


\section{Concluding remarks}

This paper has addressed the two research sub-questions posed in this paper by 1) documenting teachers' reflections on low-level positioning data as part of their inquiry process, and 2) identifying candidate metrics that could be useful for teachers to gain insight into their practice, from their positioning data. The study highlighted both opportunities and challenges that can inform the development of technologies to support research on classroom proxemics. If triangulated with other sources of evidence, positioning data could constitute a major breakthrough in the way learning spaces research is conducted and how professional reflection and development takes place. These tools provide detailed evidence that was previously impractical to gather, and open the possibility of conducting longitudinal studies. This study should be seen as initiating many more studies to transform ephemeral positioning strategies into forms of persistent evidence, amenable to computational analysis, which once suitably rendered, can provoke deeper reflection and conversations.

\section{References}

Alarifi, Abdulrahman, AbdulMalik Al-Salman, Mansour Alsaleh, Ahmad Alnafessah, Suheer Al-Hadhrami, Mai Al-Ammar, and Hend Al-Khalifa. (2016). Ultra wideband indoor positioning technologies: Analysis and recent advances. MDPI Sensors, 16(5), 1-36.

An, Pengcheng, Saskia Bakker, Sara Ordanovski, Chris LE Paffen, Ruurd Taconis, and Berry Eggen. (2020). Dandelion Diagram: Aggregating Positioning and Orientation Data in the Visualization of Classroom Proxemics. Paper presented at the CHI'20 Extended Abstracts, (pp. In press).

An, Pengcheng, Saskia Bakker, Sara Ordanovski, Ruurd Taconis, and Berry Eggen. (2018). ClassBeacons: Designing Distributed Visualization of Teachers' Physical Proximity in the Classroom. In Proceedings of International Conference on Tangible, Embedded, and Embodied Interaction, TEl'18, (pp. 357-367). ACM.

Arends, Richard. (2014). Learning to teach. New York, USA: McGraw-Hill Higher Education.

Barnard, Henry. (1854). Practical illustrations of the principles of school architecture. Ann Arbor, Michigan, United States: Norton.

Bligh, Brett. (2014). Examining new processes for learning space design. In P. Temple (Ed.), The physical university: contours of space and place in higher education, (pp. 64-87). London, UK: Routledge.

Bosch, Nigel, Caitlin Mills, Jeffrey D Wammes, and Daniel Smilek. (2018). Quantifying Classroom Instructor Dynamics with Computer Vision. In Proceedings of International Conference on Artificial Intelligence in Education, AIED'18, (pp. 30-42). Springer.

Braun, Virginia, and Victoria Clarke. (2006). Using thematic analysis in psychology. Qualitative research in psychology, 3(2), 77-101.

Brena, Ramon F, Juan Pablo García-Vázquez, Carlos E Galván-Tejada, David Muñoz-Rodriguez, Cesar Vargas-Rosales, and James Fangmeyer. (2017). Evolution of indoor positioning technologies: A survey. Journal of Sensors, 2017(2630413), 1-21.

Britton, Linda R., and Kenneth A. Anderson. (2010). Peer coaching and pre-service teachers: Examining an underutilised concept. Teaching and Teacher Education, 26(2), 306-314.

Burda, Jeffrey M, and Charles I Brooks. (1996). College classroom seating position and changes in achievement motivation over a semester. Psychological Reports, 78(1), 331-336.

Chin, Heng Buai, Cecilia Cheong Yin Mei, and Fauziah Taib. (2017). Instructional Proxemics and Its Impact on Classroom Teaching and Learning. International Journal of Modern Languages and Applied Linguistics, 1(1), 1-20.

Chua, Yi Han Victoria, Justin Dauwels, and Seng Chee Tan. (2019). Technologies for automated analysis of co-located, real-life, physical learning spaces: Where are we now? In Proceedings of International Learning Analytics and Knowledge Conference, LAK'19, (pp. 11-20). ACM. 
Damsa, Crina, and Alfredo Jornet. (2016). Revisiting Learning in Higher Education--Framing Notions Redefined through an Ecological Perspective. Frontline Learning Research, 4(4), 39-47.

Dana, Nancy Fichtman, and Diane Yendol-Hoppey. (2014). The reflective educator's guide to classroom research: Learning to teach and teaching to learn through practitioner inquiry. Thousand Oaks, $\mathrm{CA}$, United States: Corwin Press.

Derry, Sharon J., Roy D. Pea, Brigid Barron, Randi A. Engle, Frederick Erickson, Ricki Goldman, Rogers Hall, Timothy Koschmann, Jay L. Lemke, Miriam Gamoran Sherin, and Bruce L. Sherin. (2010). Conducting Video Research in the Learning Sciences: Guidance on Selection, Analysis, Technology, and Ethics. Journal of the Learning Sciences, 19(1), 3-53.

Dillenbourg, Pierre, Guillaume Zufferey, Hamed Alavi, Patrick Jermann, Son Do-Lenh, Quentin Bonnard, Sébastien Cuendet, and Frédéric Kaplan. (2011). Classroom orchestration: The third circle of usability. In Proceedings of International Conference on Computer Supported Collaborative Learning, CSCL'11, (pp. 510-517). Springer

Echeverria, Vanessa, Roberto Martinez-Maldonado, and Simon Buckingham Shum. (2019). Towards Collaboration Translucence: Giving Meaning to Multimodal Group Data. In Proceedings of SIGCHI Conference on Human Factors in Computing Systems, CHI'19, (pp. 39, 31-16). ACM.

Echeverria, Vanessa, Roberto Martinez-Maldonado, Tamara Power, Carolyn Hayes, and Simon Buckingham Shum. (2018). Where Is the Nurse? Towards Automatically Visualising Meaningful Team Movement in Healthcare Education. In Proceedings of International Conference on Artificial Intelligence in Education, AIED'18, (pp. 74-78). Springer.

Ellis, Jessica, Jessica Deshler, and Natasha Speer. (2016). Supporting institutional change: A two-pronged approach related to graduate teaching assistant professional development. In Proceedings of 19th Annual Conference on Research in Undergraduate Mathematics Education, (pp. 1-7). SIGMAA.

Erickson, Gaalen, and Anthony Clarke. (2003). Teacher inquiry: a defining feature of professional practice. In G. Erickson \& A. Clarke (Eds.), Teacher Inquiry: Living the Research in Everyday Practice, (pp. 19-26). London, UK: Routledge.

Fernandes, Amanda Careena, Jinyan Huang, and Vince Rinaldo. (2011). Does Where A Student Sits Really Matter ?-The Impact of Seating Locations on Student Classroom Learning. International Journal of Applied Educational Studies, 10(1), 66-77.

Fletcher, Jeffrey A. (2018). Peer observation of teaching: a practical tool in higher education. The Journal of Faculty Development, 32(1), 51-64.

Friend, Marilyn, Dusty Columbia Embury, and Laura Clarke. (2015). Co-teaching versus apprentice teaching: An analysis of similarities and differences. Teacher Education and Special Education, 38(2), 79-87.

Gerritsen, David, John Zimmerman, and Amy Ogan. (2018). Towards a Framework for Smart Classrooms that Teach Instructors to Teach. In Proceedings of International Conference of the Learning Sciences, ICLS'18, (pp. 1779-1782). ISLS.

Giacomin, Joseph. (2014). What is human centred design? The Design Journal, 17(4), 606-623.

Giangreco, Michael F., Susan W. Edelman, Tracy Evans Luiselli, and Stephanie Z. C. Macfarland. (1997). Helping or Hovering? Effects of Instructional Assistant Proximity on Students with Disabilities. Exceptional Children, 64(1), 7-18.

Goodyear, Peter, Robert A Ellis, and Alexi Marmot. (2018). Learning spaces research: Framing actionable knowledge. In R. A. Ellis \& P. Goodyear (Eds.), Spaces of Teaching and Learning, (pp. 221-238). Singapore: Springer.

Gunter, Philip L., Richard E. Shores, Susan L. Jack, Shirley K. Rasmussen, and Julia Flowers. (1995). On the Move Using Teacher/Student Proximity to Improve Students' Behavior. Teaching Exceptional Children, 28(1), 12-14.

Haghighi, Mohammad Moslemi, and Mahmud Mohd Jusan. (2012). Exploring students behavior on seating arrangements in learning environment: a review. Procedia-Social and Behavioral Sciences, 36, 287-294.

Hall, Edward Twitchell. (1966). The hidden dimension (Vol. 609). Garden City, NY, USA: Doubleday. 
Higgins, Steve, Elaine Hall, Kate Wall, Pam Woolner, and Caroline McCaughey. (2005). The impact of school environments: A literature review, Report. London, UK: Design Council.

Howard, Sarah K, Jie Yang, Jun Ma, Chrisian Ritz, Jiahonz Zhao, and Kylie Wynne. (2018). Using Data Mining and Machine Learning Approaches to Observe Technology-Enhanced Learning. In Proceedings of IEEE International Conference on Teaching, Assessment, and Learning for Engineering, TALE'18, (pp. 788-793). IEEE.

Imms, Wesley, Benjamin Cleveland, and Kenn Fisher. (2016). Evaluating learning environments: Snapshots of emerging issues, methods and knowledge. Rotterdam, The Netherlands: Sense Publishers.

Jones, Fredric H, Patrick Jones, and Jo Lynne Jones. (2007). Fred Jones tools for teaching: Discipline, instruction, motivation. Santa Cruz, CA, USA: Fredric H Jones \& Assocs.

Ka Yuk Chan, Cecilia. (2012). Laboratory Learning. In N. M. Seel (Ed.), Encyclopedia of the Sciences of Learning, (pp. 1705-1708). Boston, MA, United States: Springer.

Koh, Joyce H. L., and Theodore W. Frick. (2009). Instructor and Student Classroom Interactions during Technology Skills Instruction for Facilitating Preservice Teachers' Computer Self-Efficacy. Journal of Educational Computing Research, 40(2), 211-228.

Kounin, Jacob S. (1970). Discipline and group management in classrooms. Oxford, England: Holt, Rinehart and Winston.

Lim, F. V., K. L. O'Halloran, and A. Podlasov. (2012). Spatial pedagogy: mapping meanings in the use of classroom space. Cambridge Journal of Education, 42(2), 235-251.

Lockyer, Lori, Elizabeth Heathcote, and Shane Dawson. (2013). Informing pedagogical action: Aligning learning analytics with learning design. American Behavioral Scientist, 57(10), 1439-1459.

Martinec, Radan. (2001). Interpersonal resources in action. Semiotica, 135(1/4), 117-146.

Martinez-Maldonado, Roberto. (2019). I Spent More Time with that Team: Making Spatial Pedagogy Visible Using Positioning Sensors. In Proceedings of International Conference on Learning Analytics \& Knowledge, LAK'19, (pp. 21-25). ACM.

Martinez-Maldonado, Roberto, Doug Elliott, Carmen Axisa, Tamara Power, Vanessa Echeverria, and Simon Buckingham Shum. (2020a). Designing translucent learning analytics with teachers: an elicitation process. Interactive Learning Environments, 1-15.

Martinez-Maldonado, Roberto, Katerina Mangaroska, Jurgen Schulte, Doug Elliott, Carmen Axisa, and Simon Buckingham Shum. (2020b). Teacher Tracking with Integrity: What Indoor Positioning Can Tell About Instructional Proxemics. Proceedings of the ACM on Interactive, Mobile, Wearable and Ubiquitous Technologies (UBICOMP), 4(1), 1-27.

McArthur, John. (2008). Instructional Proxemics: Creating a place for space in instructional communication discourse. PhD Disertation dissertation. Clemson University, United States.

McArthur, John A. (2015). Matching Instructors and Spaces of Learning: The Impact of Space on Behavioral, Affective and Cognitive Learning. Journal of Learning Spaces, 4(1), 1-16.

Melero, Javier, Davinia Hernández-Leo, Jing Sun, Patricia Santos, and Josep Blat. (2015). How was the activity? A visualization support for a case of location-based learning design. British Journal of Educational Technology, 46(2), 317-329.

MO-SW-PBS. (2019). Missouri Schoolwide Positive Behavior Support - Tier 1 Team Workbook. University of Missouri: Missouri Department of Elementary and Secondary Education.

Munro, Michael P, and Barry H Stafford. (2012). Transforming Training in Orientation and Mobility: Examining the Effect Using an Audio-Link on the Distance Between Trainer and Trainee. International Journal of Orientation \& Mobility, 5(1), 16-27.

O'Neill, Sue C, and Jennifer Stephenson. (2014). Evidence-based classroom and behaviour management content in Australian pre-service primary teachers' coursework: Wherefore art thou? Australian Journal of Teacher Education, 39(4), 1-22.

Persico, Donatella, and Francesca Pozzi. (2015). Informing learning design with learning analytics to improve teacher inquiry. British Journal of Educational Technology, 46(2), 230-248.

Prestigiacomo, R, R Hadgraft, L Lockyer, S Knight, E van den Hoven, R Martinez-Maldonado, and J Hunter. (2020). Learning-centred Translucence: An Approach to Understand How Teachers Talk About 
Classroom Data. In Proceedings of International Conference on Learning Analytics \& Knowledge, LAK'20, (pp. 100-105). ACM.

Prieto, Luis Pablo, Kshitij Sharma, Łukasz Kidzinski, María Jesús Rodríguez-Triana, and Pierre Dillenbourg. (2018). Multimodal teaching analytics: Automated extraction of orchestration graphs from wearable sensor data. Journal of Computer Assisted Learning, 34(2), 193-203.

Raca, Mirko, Lukasz Kidzinski, and Pierre Dillenbourg. (2015). Translating head motion into attentiontowards processing of student's body-language. In Proceedings of 8th International Conference on Educational Data Mining, EDM'15, (pp. 320-326).

Robinson, Terrell E, and Warren C Hope. (2013). Teaching in Higher Education: Is There a Need for Training in Pedagogy in Graduate Degree Programs? Research in Higher Education Journal, 21, 111.

Rodríguez Triana, María Jesús, Alejandra Martínez Monés, Juan I Asensio Pérez, and Yannis Dimitriadis. (2014). Scripting and monitoring meet each other: Aligning learning analytics and learning design to support teachers in orchestrating CSCL situations. British Journal of Educational Technology, 46(2), 330-343.

Rubin, Gary N. (1972). A Naturalistic Study in Proxemics: Seating Arrangement and its Effect on Interaction, Performance, and Behavior. PhD dissertation. Bowling Green State University, United States.

Schneider, Bertrand, and Paulo Blikstein. (2015). Unraveling students' interaction around a tangible interface using multimodal learning analytics. Journal of Educational Data Mining, 7(3), 89-116.

Scott-Webber, Lennie, Jane Abraham, and Michele Marini. (2000). Higher education classroom fail to meet needs of faculty and students. Journal of Interior Design, 26(2), 16-34.

Scrivener, Jim. (2005). Learning teaching. München, Deutschland: Hueber Verlag GmbH and Company KG.

Sergis, Stylianos, and Demetrios G Sampson. (2017). Teaching and learning analytics to support teacher inquiry: A systematic literature review. In A. Peña-Ayala (Ed.), Learning analytics: Fundaments, applications, and trends, (pp. 25-63). Basel, Switzerland: Springer.

Shortland, Sue. (2004). Peer observation: A tool for staff development or compliance? Journal of Further and Higher Education, 28(2), 219-228.

Shu, Yu, Pei-Ya Zeng, Tien-Chi Huang, and Ting-Chieh Yeh. (2016). Get lost in the library?: An innovative application of augmented reality and indoor positioning technologies. The Electronic Library, 34(1), 99-115.

Slade, Sharon, and Paul Prinsloo. (2013). Learning Analytics: Ethical Issues and Dilemmas. American Behavioral Scientist, 57(10), 1510-1529.

Sousa, Maurício, Daniel Mendes, Daniel Medeiros, Alfredo Ferreira, João Madeiras Pereira, and Joaquim Jorge. (2016). Remote Proxemics. In C. Anslow, P. Campos \& J. Jorge (Eds.), Collaboration Meets Interactive Spaces, (pp. 47-73). Cham: Springer International Publishing.

Thompson, Sharon. (2012). The applications of proxemics and territoriality in designing efficient layouts for interior design studios and a prototype design studio. Masters Disertation dissertation. California State University, Northridge, United States.

Tsai, T., C. Chang, and S. Chen. (2016). Vision based indoor positioning for intelligent buildings. In Proceedings of International Conference on Intelligent Green Building and Smart Grid, IGBSG'16, (pp. 1-4). IEEE.

Wake, Jo, Fredrik Heimsæter, Edvard Bjørgen, Barbara Wasson, and Cecilie Hansen. (2018). Supporting firefighter training by visualising indoor positioning, motion detection, and time use: $A$ multimodal approach. In Proceedings of LASi-NORDIC 2018 CEUR Workshop Proceedings 2016 ; Volume 1601., (pp. 87-90).

Wang, Jian, Andong Hu, Xin Li, and Yan Wang. (2015). An improved PDR/magnetometer/floor map integration algorithm for ubiquitous positioning using the adaptive unscented Kalman filter. ISPRS International Journal of Geo-Information, 4(4), 2638-2659.

Wannarka, Rachel, and Kathy Ruhl. (2008). Seating arrangements that promote positive academic and behavioural outcomes: A review of empirical research. Support for Learning, 23(2), 89-93. 
Watanabe, Eiji, Takashi Ozeki, and Takeshi Kohama. (2018). Analysis of interactions between lecturers and students. In Proceedings of 8th International Conference on Learning Analytics and Knowledge, LAK'18, (pp. 370-374). ACM. 